Aragón en la Edad Media

XXIV (2013)

pp. $225-268$

ISSN 0213-2486

\title{
ÚLTIMAS VOLUNTADES DE MARTÍN I EL HUMANO (30 Y 31 DE MAYO DE 1410)
}

\author{
THE LAST WILL OF MARTIN I THE HUMANE, \\ KING OF ARAGON (30 ${ }^{\text {th }} / 31^{\text {st }}$ MAY 1410
}

Resumen: Se estudia un cuaderno inédito conservado en el Archivo de la Corona de Aragón que contiene el manual de las notas tomadas por el protonotario real Ramon Sescomes los días 30 y 31 de mayo de 1410, durante la agonía y muerte del rey Martín I. Este cuaderno contiene la minuta del acta de la declaración de la última voluntad del monarca sobre la sucesión en la Corona de Aragón, cuya autenticidad había sido puesta en duda por la historiografía moderna. Se incluyen además otras declaraciones y donaciones realizadas por Martín I durante sus dos últimos días de vida, cuyo conocimiento cambia la percepción que se tenía sobre el fallecimiento del último rey de la Casa de Barcelona.

Palabras clave: Martín I. Interregno (1410-1412). Compromiso de Caspe. Archivo de la Corona de Aragón.
Carlos López RodríGuez Archivo de la Corona de Aragón (ACA)
Abstract: This article investigates an unpublished register preserved in the Archives of the Crown of Aragon containing notes taken by the protonotary Ramon Sescomes on 30 and 31 May 1410 , during the agony and death of King Martin I. It contains the minutes of the last will statement about the succession of the monarch, whose authenticity had been questioned by modern historiography. This document includes statements and donations made by Martin I during his last two days of life which changes our perception of the death of the last king of the House of Barcelona.

Keywords: Martín I, Interregnum (14101412), Compromise of Caspe, Archives of the Crown of Aragon. 
Los episodios que llevaron a la crisis sucesoria abierta con la muerte del rey Martín I son tan conocidos, se han relatado y analizado en tantas ocasiones, que parece ocioso volver sobre ellos, aunque por sus consecuencias sigan alimentando los debates entre historiadores ${ }^{1}$. Aquí nos limitaremos a aportar algunos documentos desconocidos hasta la fecha, que arrojan algo de luz sobre ciertos puntos oscuros o que han dado lugar a interpretaciones equívocas.

\section{1. Últimas horas del Rey Martín I}

El día 29 de mayo de 1410, tras la cena, el monarca enfermó gravemente. Desde el 13 de mayo de ese año, había trasladado su residencia desde la torre de Bellesguard, que había adquirido a fines de 1408 por convenirle a su salud y a la cual se aficionó y que embelleció con mejoras ${ }^{2}$, al monasterio de Valdonzella, donde hasta entonces había estado de paso muy esporádicamente ${ }^{3}$. Parece que la mudanza se debió a las obras que se ejecutaban en la torre de Bellesguard ${ }^{4}$. En Valldonzella falleció hacia el mediodía del 31 de mayo ${ }^{5}$. Naturalmente, la cronística de la época se hace eco de este suceso ${ }^{6}$, tanto

1.- Antoni Furió, "Un debat inacabat: el Compromís de Casp a través de la Història”, en Martí l'Humà, el darrer rei de la dinastia de Barcelona (1396-1410). L'Interregne $i$ el Compromís de Casp. Barcelona, Institut d'Estudis Catalans [en prensa]. Agradezco al Prof. Furió su amabilidad al facilitarme la lectura de este trabajo inédito, que me ha sido muy útil. Un compendio reciente de los acontecimientos desde la muerte de Martín el Joven hasta la Sentencia de Caspe en José Ángel Sesma Muñoz, El Interregno (1410-1412). Concordia y compromiso político en la Corona de Aragón, Zaragoza, 2011. Quedo en deuda con el Sr. Javier Gómez López, bibliotecario de la Universidad Complutense de Madrid, por su eficaz ayuda bibliográfica.

2.- Francesc Carreras y Candi, "Bellesguart, real sitio de Martín I", Boletín de la Real Academia de las Buenas Letras, 1 (1901), pp. 55-64.

3.- Tenemos documentada tan solo una estancia suya en esta casa religiosa el 6 de mayo de 1401 y otra, en la que ni siquiera llegó a pernoctar, el 11 de junio de 1409 (Daniel Girona I Llagostera, Itinerari del rey en Martí (1396-1410), Barcelona, 1916, p. 232).

4.- Estas obras habían comenzado meses antes (Daniel Girona i Llagostera, "Epistolari del rey Martí d'Aragó, 1396-1410", Revista de l'Associació Artístico-Arquelógica barcelonesa, VI, núm. 62 (1913), pp. 308-309), y continuaban a mediados de mayo de 1410, según informa el propio rey (Archivo de la Corona de Aragón —en lo sucesivo, ACA-, Real Cancillería, reg. 2.237, ff. 70v y 71r).

5.- Nos consta por la clausura del proceso de las Cortes de Barcelona de 1410 (Cortes de los antiguos reinos de Aragón y de Valencia, y principado de Cataluña, publicadas por la Real Academia de la Historia, t. VI, Madrid, 1902, p. 444).

6.- Un examen exhaustivo en A. Furió, "Un debat inacabat". 
la del área de la Corona de Aragón ${ }^{7}$ como la castellana ${ }^{8}$, sin muchos datos concretos pero con bastantes juicios de valor.

La fuente cronística cercana más detallada (en realidad, la única) sobre las últimas horas del monarca es la de Lorenzo Valla, escrita hacia 1445 en el entorno de la corte de Alfonso el Magnánimo9. A él se debe la interpretación comúnmente más aceptada, que hace ver el origen de la crisis sucesoria en la predilección del rey Martín por Federico, su nieto ilegítimo, y en sus movimientos para conseguir primero su legitimación y después su proclamación como sucesor, mientras da largas a los otros candidatos, comenzando por el conde de Urgell, cosa que al final acabaría beneficiando a Fernando de Antequera. A su vez, la fuente de Valla para estos sucesos de la corte real es el conocido mosén Borra, el bufón del monarca, que lo fue también de Alfonso el Magnánimo, en cuyo círculo áulico coincidieron ambos ${ }^{10}$. Los episodios tal como los narra Valla son suficientemente sabidos: el rey enfermó gravemente tras cenar en abundancia el día 29 de mayo y, después de pasar muy mal la noche y el día siguiente, recibió, casi al filo de la medianoche del 30 de mayo, una embajada de las Cortes de Barcelona encabezada por Ferrer de Gualbes para instarle a declarar sucesor; poco antes, en un acceso, Margarita

7.- Se menciona en las llamadas crónicas de Juan I, Martín I y Fernando I (editadas por Vicent Josep Escartí, "El ms. 212 de la BUV i les cròniques de Joan I, Martí 1'Humà i Ferran I", Caplletra, 15 (1993), p. 45); en las de Pere Tomic (Historias e conquestas de Cathalunya, [Barcelona, 1886], cap. XLVI, pp. 257-258); Martín de AlPartil (Cronica actitatorum temporibus Benedicti pape XIII, ed. J. Ángel Sesma Muñoz y Ma Mar Agudo Romeo, Zaragoza, 1994, cap. XIX, p. 225); Melchor Miralles (Crònica i dietari del capellà d'Alfons el Magnànim, ed. M. Rodrigo Lizondo, Valencia, 2011, p. 159); Berenguer de PuigPardines (Sumari d'Espanya, ed. Joan Iborra, Valencia, 2000, cap. 73, p. 149); Gabriel Turell, (Recort, edición de J. Casas-Carbó i J. Massó Torrents, Barcelona, 1894, p. 137) o Pere Miquel Carbonell (Cròniques d'Espanya, ed. Agustí Alcoberro, t. II, Barcelona, 1997, pp. 159-160).

8.- Alvar García de Santa María, Crónica del rey D. Juan II, [Sevilla, 1543], cap. CIX; Fernán Pérez DE GuZmán, Crónica del señor rey don Juan, segundo de este nombre, en Castilla y en León, Valencia, 1779 , cap. XXVII.

9.- Lorenzo Valla, Historiarum Ferdinandi regis Aragoniae, París, 1521 [Valencia, 1970], lib. II. Hay traducción al español: Historia de Fernando de Aragón, ed. Santiago López Moreda, Madrid, 2002.

10.- Manuel de Bofarull y de Sartorio, "Tres cartas autógrafas é inéditas de Antonio Tallander, Mossén Borra, maestro de los albardanes de D. Fernando el de Antequera, y algunos documentos desconocidos relativos al mismo personaje", memoria ordenada por Francisco de Bofarull y Sans, Memorias de la Real Academia de Buenas Letras de Barcelona, Barcelona, t. V (1896), pp. 3-100. A Borra atribuyó Valla la anécdota sobre un último ataque de risa del rey Martín, a resultas del cual moriría, provocado por una ocurrente respuesta del bufón con un chascarrillo sobre su propio mulo que comía higos no maduros (L. Valla, Historiarum, lib. II). La fuente del episodio debe obedecer a la erudición de Valla, que parece inspirarse en las numerosas anécdotas sobre personajes famosos de la Antigüedad que murieron de risa, algunos precisamente después de haber visto a un asno comiendo higos o cardos (Stephen Halliwell, Greek Laughter: A Study of Cultural Psychology from Homer to Early Christianity, Cambridge University Press, 2008, citado por Mary BEARD, La herencia viva de los clásicos. Tradiciones, aventuras e innovaciones, Barcelona, 2013, pp. 86-87). 
de Monferrato, madre de Jaume d'Urgell, había sacudido al rey para que se pronunciara a favor de su hijo, sin éxito; mientras, los embajadores sicilianos le suplicaban que les diera a Federico como su rey; el día 31 Gualbes se presentó de nuevo con los representantes de las Cortes para levantar acta pública de la voluntad del monarca sobre que la sucesión se realizara por justicia, a lo que el rey respondió "hoc", por dos veces más, antes de fallecer ${ }^{11}$.

En honor a la verdad, Valla no se decanta categóricamente por ninguna de las causas de fallecimiento barajadas (la peste o fiebres, la ingesta bienintencionada de medicinas para estimular la procreación, los efectos de una cena abundante o la dispepsia complicada con las enfermedades que venía padeciendo el monarca), aunque se haga eco del rumor de un posible envenenamiento (mediante un ave opíparamente preparada para la cena) por mano de la esposa y la madre del conde de Urgell. Al transmitir este rumor palatino, Valla se ganó ser vilipendiado por buena parte de la historiografía catalana ${ }^{12}$. De su relato han bebido, con más o menos adornos literarios, gran parte de los historiadores posteriores a la hora de referir e interpretar los hechos del Interregno, especialmente Zurita, que fue quien gracias a su enorme prestigio más contribuyó a su difusión, si bien con más comedimiento, pues pasó por alto la alusión al envenenamiento y otras circunstancias del fallecimiento, aunque sí recogió la escena de Margarita de Monferrato sacudiendo al rey en su lecho de muerte para que declarara sucesor a Jaume d'Urgell ${ }^{13}$. Esta relación de la enfermedad, agonía y fallecimiento del rey Martín I fue reproducida a mediados del siglo XVII por Diego de Monfar (cuya obra permaneció inédita hasta $1853)^{14}$, en un contexto político muy convulso en Cataluña. Este autor añadió algunos juicios de valor de su propia cosecha, de modo que la real respuesta que Valla, a pesar de ser manifiestamente trastamarista, consideró "clara", "delicada" y "llena de afecto", se conviertió en "indeterminable", irresoluta (como ya opinó Tomic), e incluso en dejación de los derechos de su nieto ${ }^{15}$. Esta percepción iría creciendo con el tiempo. En 1855, pasados dos años de la edición de la obra de Monfar, Florencio Janer aduce como prueba "en que consta la irresolución del rey D. Martín el Humano, para nombramiento de sucesor" el acta de su última voluntad ${ }^{16}$. Fue esta una idea que caló hondo en la historiografía moderna, tanto la de orientación catalanista o urgelista,

11.- L. VAlla, Historiarum, lib. II.

12.- A. Furió, "Un debat inacabat", pp. 6 y 22.

13.- Jerónimo Zurita, Anales de la Corona de Aragón, ed. Ángel Canellas López, Zaragoza, 1978, lib. $\mathrm{X}, 91$.

14.- Diego de Monfar y Sors, Historia de los Condes de Urgel, t. II, Barcelona, 1853, pp. 336-338.

15.- D. de Monfar, Historia de los Condes de Urgel, pp. 338-342.

16.- Florencio JANER, Examen de los sucesos y circunstancias que motivaron el Compromiso de Caspe, Madrid, 1855, pp. 10 y 11. 
como en la de tendencia castellanista o trastamarista, que se formaron en el contexto ideológico del nacionalismo, añadiendo tintes negativos (indecisión, obstinación, irresponsabilidad), a la actuación de Martín I por su empeño en favorecer a su nieto ilegítimo ${ }^{17}$. Culminó con la obra de Daniel Girona i Llagostera, médico, historiador y dirigente de la Unió catalanista, quien sin más datos que los proporcionados por Valla supuso que Martín I murió de un ataque de coma urético, producido por los efectos que tuvo un régimen de alimentación fuerte (para inducir la procreación) sobre un hombre obeso, enfermo de cuartanas y probablemente diabético ${ }^{18}$. Todo ello le hace dudar de que realmente estuviera en la plenitud de sus facultades mentales cuando contestó a las preguntas contenidas en el acta de su última voluntad, por lo que supone que fue falsificada por los enemigos del conde de Urgel. Esta versión conspirativa de los hechos fue aceptada por un catalanismo político que se identificaba retrospectivamente con el urgelismo como opción nacional, antes y después de la Guerra Civil, hasta consagrarse con Ferran Soldevila ${ }^{19}$ (quien atribuyó la maniobra a Violante de Bar) y continuar hasta hoy ${ }^{20}$.

\section{Dudas SOBRE LA AUTENTICIDAd DEL ACTA DE LA Última DEClaRACióN DEL REY MARTÍN I}

El acta con la última voluntad del rey Martín I, a la cual se refirió ya Valla, tuvo una importancia capital en el desencadenamiento de los sucesos del Interregno y en su desenlace final. El primero en editarla fue Diego de Monfar, a mediados del siglo XVII. Su fuente fue un traslado notarial que se leyó en la sesión del Parlamento catalán de 22 de octubre de 1411. La

17.- Víctor Balaguer, Historia de Cataluña y de la Corona de Aragón, t. III, Barcelona, 1862, p. 330; Antonio de Bofarull y Brocá, Historia crítica (civil y eclesiástica) de Cataluña, t. V, Barcelona, 1877, pp. 137-140; Pablo Piferrer y Francisco Pi Margall, Cataluña, en España. Sus monumentos y artes. Su naturaleza e historia (con notas y adiciones de Antonio Aulestia Pijoan), t. I, Barcelona, 1884, p. 366; Antoni Aulèstia y PiJoAn, Història de Catalunya, vol. I, Barcelona, 1887, p. 385; Modesto Lafuente, Historia general de España, desde los tiempos primitivos hasta la muerte de Fernando VII, t. V, Madrid, 1888, p. 232; Joaquim MireT I SANS, "El darrer rei de la casa de Barcelona”, en Homenatge a la memòria del rei Martí(Vè. Centenari de la seva mort). Conferencia llegida en el Centre Excursionista de Catalunya el dia 24 de maig de 1910, pp. 14-15.

18.- Daniel Girona i Llagostera, "L'acta de darrera voluntad del Rey En Martí", Revista de Catalunya (1921), pp. 275-279 y 299-302.

19.- Ferran Soldevila, Història de Catalunya, vol. II, Barcelona, 1962, pp. 563-564, y n. 63; IDEM, El Compromís de Casp (Resposta al Sr. Menéndez Pidal), Barcelona, 1965, pp. 32-33.

20.- Las más recientes, Josep-David Garrido I VALls, Vida i regnat de Martí I, l'últim rei del casal de Barcelona, Barcelona, 2010; y Ernest Belenguer CeBrià, El com i el perquè del Comprimís de Casp (1412): història i debat, Barcelona, 2012, pp. 41-42, aunque con reservas críticas. 
obra de Monfar no vio la luz hasta 1853, gracias a Próspero de Bofarull ${ }^{21}$. Unos años antes, el propio Bofarull la había publicado según la copia que se encuentra en el ACA, Real Cancillería, Procesos de Cortes, núm. 18, fols. $1057 \mathrm{v}-1059 \mathrm{r}$, que se corresponde con la sesión del 22 de octubre de 1411 ya mencionada ${ }^{22}$. En 1855 la publicó de nuevo Florencio Janer ${ }^{23}$, pero sin citar su fuente y suprimiendo las suscripciones notariales. La editó otra vez en 1862 Víctor Balaguer ${ }^{24}$, sin mencionar tampoco su fuente, que fue Janer. Como parte integrante del volumen 18 de los Procesos de Cortes del ACA, fue publicada una vez más por la Real Academia de la Historia, en $1904^{25}$. A partir de esta edición ha sido publicada en muchas ocasiones ${ }^{26}$ y parafraseada muchas más. Su original, sin embargo, no estaba localizado, lo que ha dado lugar a interpretaciones que en seguida examinaremos.

Como es bien sabido, en el acta se contiene cómo el día 30 de mayo, hacia las once de la noche, compareció ante el rey Martín, enfermo en la cámara llamada de la "Abadesa" del monasterio de Valldonzella, una representación de las Cortes catalanas encabezada por Ferrer de Gualbes, consejero de Barcelona, pero cuyos miembros no se especifican, y preguntó al rey si quería que la sucesión de los reinos, después de su muerte, fuera para aquel al que correspondiera "por justicia", a lo cual el monarca contestó afirmativamente con un simple "hoc". Al día siguiente, 31 de mayo a hora de tercia, se presentó de nuevo esta comisión y Gualbes reiteró su pregunta añadiendo si deseaba que de su respuesta se hiciera carta pública. El rey de nuevo contestó con el monosílabo "hoc". Esta pregunta fue repetida otra vez por el protonotario real, Ramon Sescomes, y se obtuvo la misma respuesta. Finalmente, el protonotario levantó el acta, que fue firmada por varios testigos.

$\mathrm{Su}$ contenido fue ya mencionado en julio de 1410 por el gobernador de Cataluña ${ }^{27}$, aunque este documento no se conoció por el original sino a través de un traslado notarial de 29 de julio de $1411^{28}$, que fue redactado a petición del parlamento catalán en su sesión de 2 de julio de $1411^{29}$. El acta fue

21.- D. de Monfar, Historia de los Condes de Urgel, pp. 340-342.

22.- En Colección de documentos inéditos del Archivo de la Corona de Aragón, t. I, Barcelona, 1847, doc. LXI.

23.- F. JANER, Examen de los sucesos, apéndice XVI, pp. 125-126.

24.- Víctor Balaguer, Historia de Cataluña, t. III, apéndice IX, pp. 397-398.

25.- Cortes, t. VIII, Madrid, 1904, pp. 481-483.

26.- La última, por Francisco M. Gimeno Blay, El Compromiso de Caspe (1412). Diario del Proceso, Zaragoza, 2012, pp. 451-453, siempre según el Proceso de Cortes del ACA, vol. 18.

27.- F. Soldevila, El Compromís de Casp, pp. 51-57.

28.- D. de Monfar, Historia de los Condes de Urgel, p. 342, leyó bien la fecha. Se confunde F. M. Gimeno Blay, El Compromiso de Caspe, p. 453, al adelantarla al 29 de junio.

29.- Cortes, t. VIII, Madrid, 1904, pp. 266. 
solicitada el 10 de octubre por Joan Dezplà, embajador del Parlamento de Cataluña ante el parlamento aragonés reunido en Alcañiz ${ }^{30}$. El 22 de octubre se leyó el traslado de 29 de julio de 1411 ante el parlamento catalán, que no se contentó con esta copia que los diputados de la Generalitat habían podido obtener del antiguo protonotario Ramon Sescomes sino que acordó examinar el instrumento original ${ }^{31}$. En la sesión de 31 de octubre de 1411 se leyó una carta enviada al Parlamento por los diputados de la Generalitat en la que se relataba que no habían conseguido el instrumento original porque Sescomes alegaba no haber sido pagado aún. A esta carta el Parlamento respondió ordenando que se le dieran 500 florines de Aragón, 200 por ese instrumento y 300 más que se le adeudaban por otros trabajos ${ }^{32}$. El protonotario respondió en persona, acudiendo ante el Parlamento en Tortosa, el $1^{\circ}$ de diciembre, para reiterar que ya había presentado un traslado y exponiendo que había razones para no mostrarlo en su forma original, a no ser ante todos los parlamentos congregados y sólo si antes se le pagaba convenientemente. El Parlamento se conformó, pues no urgía el original al disponer de un traslado auténtico ${ }^{33}$. De nuevo el 31 de marzo de 1412, el arzobispo de Tarragona y Bernat de Gualbes, jueces compromisarios, escribieron desde Caspe para solicitar al Parlamento de Cataluña algunos documentos, entre ellos "la carta que fonch feta de la disposició de la successió remesa a la justícia rehebuda per lo dit En Comes" 34 . Pero todavía el 14 de abril los diputados del General reconocieron que debían 10.000 sueldos a Sescomes por sus salarios, por lo que aún faltaba el traslado del testamento del rey Martín, en poder del antiguo protonotario ${ }^{35}$. Aunque el 9 de mayo de 1412 los tres compromisarios catalanes en Caspe (Pere Sagarriga, arzobispo de Tarragona; Guillem de Vallseca y Bernat de Gualbes) solicitaron de nuevo el acta, tuvieron que conformarse con una copia auténtica, sin pretender examinar el instrumento original ${ }^{36}$. Las reticencias de

30.- Cortes, t. VIII, p. 460.

31.- Cortes, t. VIII, pp. 481-483.

32.- Cortes, t. IX, p. 8. Estos 300 florines se le debían a él y a su sustituto por sus salarios por acuerdo del Parlamento de 18 de abril de 1411 (Cortes, t. VIII, p. 66).

33.- Cortes, t. IX, p. 113.

34.- Federico Udina Martorell, "El 'Codex de Tortosa' i els testaments dels comtes de la casa de Barcelona”, Analecta sacra tarraconensia, 71 (1998), pp. 865-875. Esta carta se leyó ante el Parlamento de Cataluña en la sesión de 6 de abril (Cortes, t. X, Madrid, 1906, pp. 28 y 31-32), y la petición se trasladó a los diputados del General el 7 de abril (ibídem, pp. 34-37).

35.- Sesión de 18 de abril de 1412 (Cortes cit., t. X, pp. 74-76).

36.- El 13 de mayo de 1412, se lee la carta enviada al Parlamento por el arzobispo de Tarragona, Vallseca y Gualbes, datada en Caspe a 9 de mayo, notificando que han recibido algunos de los documentos pedidos, "mas fallnos la renunciacio de la reyna de Castella e lo translat de la ordinacio que lo senyor rey en Marti feu que succehis a qui per justicia se pertanyerie" (Cortes, t. X, p. 147). En la sesión de 17 de mayo, el Parlamento de Cataluña decidió trasladar a los diputados del General la petición de los compromisarios (ibídem, pp. 161-162). En la sesión de 28 de mayo, se leyó la respuesta de 
Sescomes a entregar un original sin que se le pagaran antes sus cuantiosos salarios han dado pie a toda clase de especulaciones historiográficas.

En efecto, todo ello llevó a Girona i Llagostera a cuestionar su veracidad para considerarla una falsificación o manipulación de la época. A la luz de esta presunción interpreta las peticiones del Parlamento de Cataluña y las respuestas dilatorias dadas por el protonotario Sescomes. A estas añade otras objeciones: el hecho de que en ninguna de las sesiones de Cortes se menciona la elección de Ferrer de Gualbes ni los otros electos para que los representasen ante el rey en su lecho de muerte; el que los brazos eclesiástico y militar no estuviesen representados en esa comisión; que las cuestiones sobre la sucesión se planteasen con tanta vaguedad y con fórmulas poco prolijas; o que la respuesta del monarca fuese tan breve, lo que hace sospechar que el soberano se encontraba en un estado de inconsciencia moral y de insensibilidad física, privado del uso cabal de su conocimiento. Todo fue posible porque el monarca moribundo estaba rodeado de acérrimos enemigos de Jaume d'Urgell, que son los testigos que firman al pie del documento y que urdieron esta hábil intriga antiurgelista para manipular la voluntad real, conspiración que fue la que movió el proceso hasta culminar, merced a las maquinaciones del papa Benedicto XIII y del infante Fernando de Castilla, en la sentencia de Caspe ${ }^{37}$. La hipótesis de la falsificación del acta tuvo amplia y rápida acogida entre los historiadores catalanes de mediados del siglo XX, que defendían la candidatura urgelista: el nacionalista Ernest Moliné y Brases ${ }^{38}$, Félix Durán i Cañameras ${ }^{39}$, Vicens Vives ${ }^{40}$, e incluso alguien tan trastamarista como Manuel Dualde $^{41}$. Por aquellos años, sólo Ramón Menéndez Pidal defendió con firmeza su autenticidad ${ }^{42}$. La opinión de considerar su elaboración como una impostura que respondía a una conspiración antiurgelista alentada por la reina

los diputados que dicen tener ya algunos documentos de los que piden, pero todavía les faltan otros (ibídem, p. 195).

37.- D. GironA, "L'acta", pp. 275-279 y 299-302.

38.- A. Aulèstia, Història de Catalunya, anotada y continuada por Ernest Moliné y Brases, vol. I, p. 385.

39.- Félix Durán i Cañameras, Margarida de Prades, Barcelona, 1956, pp. 15-16, que concluye: "Aquest punt és un dels més foscos dels que hi ha en lo atenyent als darrers moments del rei Martí. De totes maneres, l'acta en la que constava la voluntat del rei Martí de que fos rei aquell a qui de dret i de justicia pertanyia, no va a arribar a poder dels compromissaris de Casp i mai ningú l'ha vista".

40.- Jaume Vicens Vives, Els Trastàmares, Barcelona, 1956, p. 79: “tothom està d'acord a considerar apòcrifa l'acta en què es manifestà la suposada voluntat del rei Martí'.

41.- Manuel Dualde Serrano, "La Concordia de Alcañiz" en Anuario de Historia del Derecho Español, XVIII (1947), p. 265; Ídem y José Camarena, El Compromiso de Caspe, Zaragoza, 1971, pp. 46-49.

42.- Ramón Menéndez Pidal, "El Compromiso de Caspe. Autodeterminación de un pueblo", en Historia de España, t. XV, Los Trastámaras de Castilla y Aragón en el siglo XV, Madrid, 1964, especialmente pp. XXXVIII-XLIV. 
Violante para favorecer a su nieto Luis de Calabria se impuso gracias a Ferran Soldevila quien, en su respuesta a Menéndez Pidal, dedicó muchas páginas y muy apasionadas a demostrar la falsedad de este documento, haciéndose eco de los razonamientos de Girona ${ }^{43}$. Tras exponer las maniobras dilatorias del protonotario Ramon Sescomes y otros compromisarios para entregar el acta reclamada por el Parlamento de Cataluña (que califica de "comedia"), concluye: "L'acta original pogué continuar en l'inconegut i hi continua encara, perquè aquesta és l'hora que no ha aparegut" 44 .

Pero el original del acta de la última voluntad del rey Martín I existe y está localizada. Y va acompañada con otros documentos no menos interesantes.

\section{El Cuaderno de últimas voluntades del Rey Martín I}

Siempre se ha tenido clara conciencia de las tremendas consecuencias políticas de la escueta respuesta ("hoc") dada por Martín el Humano. Por su importancia, el acta en la que se consignó su última voluntad adquiere un valor extraordinario. Como se desconocía el paradero del original, se pudo poner en cuestión su autenticidad. Sorprendentemente, se encuentra consultable desde mediados del siglo XIX, encuadernada en un volumen del ACA con la signatura: Generalidad, vol. 962, fols. 23-25 y 38, de la segunda numeración inferior. Debo este hallazgo a un informe oficial del Sr. Jaume Riera, archivero del ACA, evacuado en el año 2009.

Se trata de un volumen misceláneo en el que se mezclaron hasta cinco cuadernos y varios papeles sueltos procedentes del fondo documental de la Generalidad de Cataluña, que ingresó muy desordenado en el ACA en 1828. Debieron encuadenarse juntos cuando se clasificaron y reordenaron las series documentales de este fondo, en tiempos del archivero Manuel de Bofarull. Entonces se dio al volumen resultante el título: "Corts de 1409", aunque en 1985 se advirtió el error y su naturaleza miscelánea, indicando con claridad cada una de las piezas que lo integraban. Encabezando el primer cuaderno, figura la nota antigua que sigue: "Lo dedit proces es ya en lo proces gros

43.- F. Soldevila, El Compromís de Casp, pp. 31-68. Esta visión conspirativa ha calado tanto que la recoge recientemente J. A. SESMA MuÑoz, El Interregno, pp. 47-52, quien al analizar la elaboración de la mencionada acta — sin plantearse su autenticidad, que da por supuesta - califica los acontecimientos del 30 y 31 de mayo y la visita de la comisión encabezada por Ferrer de Gualbes como "golpe de mano, ejecutado por un miembro del patriciado urbano barcelonés, amparado en el prestigio de las Cortes y respaldado por un grupo reducido de caballeros muy próximos al entorno de Martín el Joven y, tras su muerte, al del rey".

44.- F. Soldevila, El Compromís de Casp, pp. 68. Recientemente, F. M. Gimeno Blay, El Compromiso de Caspe, pp. 451-453, indica que el original está en "paradero desconocido". 
de dita cort, comensa en lany 1405 y passe fins lany 1410 , sino es a la fi en fulles 74 en auall que son les donas fettes per dit rey". Con el término "procés gros" se refiere al conjunto de procesos existentes en una gran caja de madera que a fines del siglo XVI se conocía en los inventarios del Archivo Real de Barcelona como "Procés Gros fet sobre la electió feta per les nou persones... eletes per a investigar, dicesir y publicar la successió de la corona real de Aragó". Este proceso contenía las actas de los compromisarios de Caspe, en borrador y en limpio, unidos ambos ejemplares al proceso del Parlamento de los catalanes ya en el siglo XVI. Fue extractado por Próspero de Bofarull, en 1848, para abrir la "Colección de Documentos Inéditos del Archivo de la Corona de Aragón". Después, fue la fuente para la edición preparada por la Real Academia de la Historia, entre 1903 y 1906, en los tomos VII-X de la colección "Cortes de los antiguos reinos de Aragón y Valencia y principado de Cataluña", que es la que han manejado los historiadores desde entonces ${ }^{45}$. Un investigador apresurado que hojeara el volumen N-962 del fondo de la Generalidad y tropezara con la advertencia de la primera hoja de que su contenido (referido en realidad al primer cuaderno de este libro misceláneo) estaba incluido en el "Procés gros", y por tanto, ya editado modernamente, lo haría a un lado para buscar otra documentación inédita.

Concentremos nuestra atención en el segundo cuaderno de este volumen que, como se advierte en la moderna nota archivística puesta al principio del libro, se trata de un "Capbreu o manual de notes preses el dia de la mort del rei Martí pel seu protonotari Ramon ses-Comes, amb postil·les del jurista Esperandéu Cardona" tomadas los días 30 y 31 de mayo de 1410. Sabemos que el notario Sescomes, de quien no se conserven protocolos en los archivos notariales ${ }^{46}$, ocupó este oficio en la cancillería de Martín I cuando fue infante. Ya por entonces tenía la costumbre de redactar los documentos a su cargo directamente sobre los registros, de manera que estos se encuentran llenos de correcciones ${ }^{47}$. Veremos que este es el caso del cuaderno que nos ocupa, lo que añade a su valor histórico un interés extraordinario. Sescomes se promociona como protonotario real cuando Martín fue coronado y se mantuvo en el cargo con Fernando ${ }^{48}$.

45.- Su descripción detallada en Beatriz Canellas Anoz, "Actas de los Parlamentos de Cataluña y Aragón tras la muerte de Martín el Humano y del Compromiso de Caspe y elección de Fernando de Antequera", en La Corona de Aragón en el centro de su historia, 1410-1412. El Interregno y el Compromiso de Caspe, Zaragoza, 2012, pp. 13-14.

46.- F. Durán, Margarida de Prades, p. 16.

47.- Jaume Riera I SAns, "El baptisme de Rabí Ishaq ben Seset Perfet", Calls, 1 (1986), p. 46.

48.- Josep Trenchs y Antonio Ma Aragó, Las cancillerías de la Corona de Aragón y Mallorca desde Jaime I a la muerte de Juan II, Zaragoza, 1982, p. 58. 
El cuaderno tiene formato folio, a excepción de las dos hojas que se especificarán, y se encuentra en buen estado, salvo por la humedad que ha manchado la esquina superior derecha, afectando las tintas. El manual de Sescomes contiene las notas o documentos que se resumen en la relación que sigue, en la cual se indican los folios, según la numeración moderna del cuaderno - a lápiz, en el margen inferior derecho- más su equivalencia con la antigua del volumen entero, si la tiene:

[a] 26 de agosto de 1443. Mandato del veguer de Barcelona al notario Joan Despujol para que se libre a Eleonor de Cervelló el traslado de la donación de la torre de Bellesguard, hecha mortis causa por el rey Martín a favor de la reina Margarita el 31 de mayo de 1410. [F. Ar-v]. $14,5 \times 22 \mathrm{~cm}$.

1. 31 de mayo de 1410. "Domine regine Margarita donacio causa mort[is] eidem facta per regem quondam". F. 1r-v (= ff. 73 y 74r-v: se dieron dos números para el mismo folio). [Sigue en el núm. 7].

2. 31 de mayo de 1410. El rey Martín restituye al abad y convento de Santa Maria de Ripoll la posesión y jurisdicción criminal de las villas y parroquias de Sant Esteve d'Olot, Sant Cristòfol les Fonts y Sant Andreu del Coll. F. 2r-v (= f. 75r-v).

3. 31 de mayo de 1410. El rey Martín, en descargo de su conciencia, reintegra a Joana, condesa de Ampurias, la jurisdicción de Vinçà, en la veguería de Conflent, que había ocupado indebidamente a su marido, el difunto Pere, conde de Ampurias. F. 3r-v (= f. 76r-v).

4. 31 de mayo de 1410. El rey Martín, por causa de sus muchos servicios, hace donación ínter vivos, en plena propiedad, del castillo de Juià, sito en la veguería de Gerona, a favor de su consejero y mayordomo Ramon de Blanes. Ff. 4r-5v (= ff. 75r-78v).

5. [30 de mayo de 1410]. Acta de la confirmación del testamento de Martín I a favor de su hijo Martín de Sicilia, y de la donación mortis causa a la reina Margarita. F. 6r-v (= ff. 79r-v).

6. Sin data [30-31 de mayo de 1410]. Apostillas de Esperandéu Cardona. F. $7 \mathrm{r}-\mathrm{v}(=\mathrm{f} .80 \mathrm{r}-\mathrm{v})$.

7. 31 de mayo de 1410. [Final del núm. 1]. F. 8r-v (=f. 81r-v).

8. 31 de mayo de 1410. Esta pieza contiene dos instrumentos. El primero (f. 9r-v) consiste en un documento incompleto, sin data, mediante el cual el rey Martín, sin hacer mención a su enfermedad, restituye a Guillem Ramon de Moncada en el marquesado de Malta y condado de Augusta que fueron confiscados a su padre, [Guillem] Ramon de 
Moncada, por Martín el Joven. El encabezamiento ("Petro de Sancto Minato, militi, pro castro de Pals") se refiere al segundo documento, (que comienza al f. 9v, a continuación del anterior), datado el 31 de mayo de 1410, mediante el cual el rey Martín I empeña a Pere de Sentmenat, su camarero y mayordomo, el castillo de Pals con todos sus derechos y pertenencias. Ff. 9r-12v (= ff. 82r-85v).

9. 31 de mayo de 1410. "Donacio Regni Sicilie facta Egregio Ffrederico". Ff. 13r-16v (= ff. 86r-89v).

10. 31 de mayo de 1410. El rey Martín hace donación mortis causa de 20.000 florines de oro a Pere de Cervelló, su consejero y mayordomo, que se harán efectivos solo en caso de fallecer el monarca (f. 17r). En el documento que sigue a este, el rey Martín I hace donación ínter vivos al mismo Pere de Cervelló de otros 20.000 florines de oro (f. 17v). F. $17 \mathrm{r}-\mathrm{v}(=\mathrm{f} .90 \mathrm{r}-\mathrm{v})$.

11. 31 de mayo de 1410. El rey Martín hace donación vitalicia de la alcaidía del Real de Valencia y su capilla, vacante por muerte de Gil de Puig, a favor de su camarero Luis Aguiló. F. 18r-v (= f. 91r-v).

12. Sin data [31 de mayo de 1410]. Nombramiento de Pere de Torrelles como tutor de Federico de Aragón y administrador en su nombre del reino de Sicilia, y juramento que por él hace Ramon de Torrelles. [Sigue en el núm. 19]. F. 19r-v (= f. 92r-v).

13. Sin data [31 de mayo de 1410]. El rey Martín hace donación ínter vivos, en pleno alodio, a su camarero Ramon de Torrelles de las rentas y derechos reales percibidos en Calatayud, una vez que concluya el usufructo vitalicio que sobre ellas percibe su esposa, la reina Margarita. F. 20r-v (= f. 93r-v).

14. 31 de mayo de 1410. El rey Martín, por descargo de su conciencia, restituye a Guillem Ramon de Moncada el marquesado de Malta, como heredero de su padre, Guillem Ramon de Moncada, a quien fue expoliado por Martín el Joven. Firman como testigos presentes en este acto: fray Miquel de Quintana, electo de Monreale de Sicilia, confesor; fray Berenguer de Rajadell, abad de Ripoll; Roger de Moncada, camarlengo; Pere de Cervelló, mayordomo; Ramon de Sentmenat, camarero; Francisco de Aranda, donado de Portacoeli, Luis Aguiló, camarero. Figura tachado Guerau Alemany de Cervelló, gobernador de Cataluña. Ff. 21r-22v (= ff. 94r-95v).

15. 30 y 31 de mayo de 1410. Acta de la última voluntad de Martín I sobre la sucesión de sus reinos. F. 23r-v (= sin número de folio). 21 x $22,5 \mathrm{~cm}$. 
16. Sin data [30-31 de mayo de 1410]. Acta de la declaración de Martín I sobre el gobierno de Cataluña y los oficiales trienales. F. 24r-v (= f. $96 r-v)$.

17. 30 de mayo de 1410. Acta de la confirmación del testamento de Martín I a favor de su hijo Martín de Sicilia, y de la donación mortis causa a la reina Margarita. F. 25r-v (= f. 97r-v).

18. En blanco. F. 26r-v (= f. 97r-v).

19. [Final del núm. 12]. F. 27r-v (= f. 98r-v).

20. Sigue inserto el cuaderno núm. III del volumen misceláneo, constituido por el "Procés informatiu sobre l'administració passada dels Diputats, incoat en virtud d'una comissió reial firmada el 15.I.1432." Ff. 99 a 109 de la numeración original.

21. 31 de mayo de 1410. El rey Martín hace donación mortis causa a Ramon de Sentmenat, en recompensa por sus servicios, del mero y mixto imperio, y toda la jurisdicción civil y criminal, alta y baja, sobre Polinyà, y sobre los mansos que posee en la parroquia de Santa Maria de Santiga, en la veguería del Vallès. Ff. 28r- 29v (= ff. 110r-111v).

22. 31 de mayo de 1410. El rey Martín hace donación ínter vivos a Ramon de Torrelles, en recompensa por sus servicios, del dominio directo y derecho alodial sobre el castillo de La Roca [del Vallès], el cual poseía Torrelles por compra. Ff. 30r-31v (= ff. 112r-113v).

23. 31 de mayo de 1410. El rey Martín dona a Ramon de Sentmenat la primera castellanía o alcaidía vacante en el principado de Cataluña y reino de Mallorca. F. 32r-v (= f. 114r-v).

24. 31 de mayo de 1410. El rey Martín hace donación ínter vivos a Berenguer Arnau de Cervelló del dominio directo y alodial sobre los castillos de Vilademàger, Pontils y Santa Perpètua, que ahora posee por donación paterna Martí Joan de Cervelló, su hijo. Ff. 33r-34v (= ff. $115 \mathrm{r}-116 \mathrm{v})$.

25. 31 de mayo de 1410. El rey Martín, por descargo de su conciencia, reintegra el puerto de Canet a Pere de Fenollet, vizconde de Illa y Canet, a quien había sido confiscado. F. 35r-v (= f. 117r-v).

26. 31 de mayo de 1410. El rey Martín hace donación a Ramon de Sentmenat, por su vida y la de un hijo, de la alcaidía de la casa real de Valldaura, con un salario anual de 1.500 sueldos barceloneses. Ff. $36 \mathrm{r}-37 \mathrm{v}$ (= ff. $118 \mathrm{r}-119 \mathrm{v})$.

27. 30 y 31 de mayo de 1410. Traslado del acta notarial de la última voluntad del rey Martín I sobre la sucesión de sus reinos, realizado el 29 de julio de 1411. F. 38r-v (= f. 120r-v). 
Merced al primer documento, señalado con la letra [a], que precede al cuaderno pero que no forma parte de él, sabemos que las escrituras del protonotario Ramon Sescomes fueron a parar a manos de Joan Despujol, notario y escribano real, el cual en 1410 era sustituto del protonotario, y en cuyo poder estaban al menos en 1443, cuando a instancias de la entonces propietaria de la torre de Bellesguard, Elionor de Cervelló, inmersa en pleitos con algunos acreedores del rey Martín, se solicitó un traslado de la donación de Bellesguart que este monarca había hecho en su lecho de muerte a favor de su esposa la reina Margarita. Las vías por las cuales este cuaderno llegó después al archivo de la Generalitat nos son desconocidas por ahora.

Todos los documentos están datados los días 30 y 31 de mayo, lo que deja ver que hubo una gran actividad en torno al monarca moribundo. Se desvanece así la imagen que teníamos hasta ahora, en la cual unos episodios trascendentes habían transcurrido sin dejar rastros documentales. Ciertamente, hasta el mismo 31 de mayo se fechan todavía varias sentencias y otros actos de la Audiencia real (ubicada en el Palacio real de Barcelona), expedidos en nombre del monarca si bien firmados por Bonanat Pérez, regente la cancillería; por Esperandéu Cardona, el vicecanciller, o por otros oficiales ${ }^{49}$. Sin embargo, el grueso de documentos suscritos por el soberano en persona se interrumpe el 27 de mayo de $1410^{50}$. Sólo firmó tres el 28 de mayo. En dos de ellos, se ordenaba entregar a la reina Margarita las cortinas de raso de "drap d'Espanya" del difunto infante Martín (que posiblemente llevarían sus armas) ${ }^{51}$. En otro se libraba una importante cantidad en Sicilia a Ramon de Torrelles, quien tuvo a su cargo a Federico de Aragón durante el Interregno ${ }^{52}$. Acaso estos documentos pudieran estar en relación con la solemne ceremonia de legitimación de Federico que, según Valla, se preparaba para tres días más tarde, el domingo $1^{\circ}$ de junio. Precisamente sobre su nieto trataban dos de las tres cartas registradas que el rey Martín firmó el 29 de mayo (quizá antes de la cena fatal). En ellas agradecía al médico Francesc de Granollac y al caballero Antoni Torrelles las noticias sobre la buena salud de Federico, conde de Luna, y les encarecía su cuidado ${ }^{53}$. Hay

49.- En ACA, Real Cancillería, reg. 2.280, f. 191v; reg. 2.271, ff. 91v-92v; reg. 2.304, f. 144r.

50.- Por ejemplo, el registro "Secretissimum et secretorum", que comienza en el f. 107 del reg. 2.313.

51.- ACA, Real Cancillería., reg. 2.237, f. 72r-v.

52.- ACA, Real Cancillería, reg. 2.185, f. 132v.

53.- ACA, Real Cancillería, reg. 2.237, f. 73r. Publicadas en Colección, t. I, doc. LX, p. 208; y en D. Girona, Itinerari, p. 244. Cfr. Antoni Closas i Abat, El nét del rei Martí, Barcelona, 1972, pp. 36-37. La tercera carta registrada del día 29 de mayo firmada por Martín I era una orden de pago girada contra el tesorero de Sicilia a favor de Luis de Vilarasa, consejero real (ACA, Real Cancillería, reg. 2.325, f. 77r-v). Este caballero valenciano era ujier de armas del rey en 1410 (María Teresa Ferrer i Mallol, "El Consell reial durant el regnat de Martí l'Humà", en XV Congreso de Historia de la Corona de Aragón, vol. 1-2, Zaragoza, 1996, p. 189). 
otro intrigante documento firmado el 29 de mayo, del cual se conserva el original: se trata de una carta credencial ante el rey Ladislao de Nápoles a favor de Dionisio d'Òdena, para tratar de ciertos asuntos que no se especifican ${ }^{54}$. Lo más sorprendente es que el único documento firmado por Martín I y despachado a través de la cancillería el día 30 de mayo, durante su agonía (la cual, por lo que dice Valla, fue larga y dolorosa) se refiera a la busca y captura de un esclavo doméstico que se ha fugado de Bellesguard ${ }^{55}$. ¿Por qué huía y por qué el rey distrae sus últimas fuerzas, poco antes de expirar, para ordenar el apresamiento de este hombre? Nunca lo sabremos. Sin salir de las suposiciones, podemos pensar que los rumores, verídicos o infundados, sobre la muerte del rey corrían ya en la corte durante su agonía. Rumores que no han dejado rastros documentales y que abrieron las puertas a todas las sospechas.

Con el cuaderno de últimas voluntades del rey Martín I a la vista, lo primero que llama la atención es la abundancia de escrituras otorgadas por el soberano en su agonía, lo que contradice el espeso silencio documental en el que hasta ahora parecía sumido el moribundo y que, en opinión de varios historiadores, se debía a su supuesto estado de insensibilidad física y psíquica. Constatamos pues que, con independencia de la habitual fórmula notarial que deja constancia de la plena conciencia del moribundo para validar sus últimos actos jurídicos, el rey Martín desplegó una notable actividad durante sus últimas horas. $\mathrm{O}$, al menos, en torno suyo se desplegó una notable actividad jurídica. Procedamos por orden de importancia de los documentos.

\section{El oRiginal del acta con la Última voluntad de Martín I}

En primer lugar, señalado con el núm. [15], hallamos el original de la nota o minuta del acta de la que se ha considerado la última voluntad del rey Martín I, un papel de $21 \mathrm{~cm}$. de ancho por $22,5 \mathrm{~cm}$ de alto, con el texto redactado y tomado al vivo por el protonotario Sescomes, cuya existencia se puso en duda. A esta se refiere con cierto detalle el tantas veces citado traslado que fue presentado al parlamento catalán en 22 de octubre de 1411,

54.- ACA, Real Cancillería, Cartas Reales de Martín I, núm. 1.284.

55.- "Lo Rey. Batle. Segons que havem entes vos haveu pres aqui un sclau nostre sard lo qual era fuyt no ha molts dies de la nostra casa de Bellesguard. Per que us manam que de continent, vista la present, nos enviets aquell per persona certa e ben segura. E aço per res no mudets. Dada en lo Monestir de Valldonzella sots nostre segell secret a XXX dies de maig del any M CCCC X. Rex Martinus. [Al pie:] Dirigitur. Dominus Rex mandavit mihi Petro de Torrente." (ACA, Real Cancillería. reg. 2.237, f. 73r). Ese mismo día, el vicecanciller Cardona firma, por mandato regio, una autorización al maestre racional para aceptar el recibo de los gastos sufragados por el tesorero para el cobro de la dote de Isabel, condesa de Urgel (ACA, Real Cancillería, reg. 2.262, f. 106r). 
como existente en el protocolo o libro de notas del protonotario Sescomes ${ }^{56}$, que es precisamente el que estamos examinando. El documento tiene todos los visos de ser auténtico, con tachaduras y enmiendas, y sin las fórmulas notariales de encabezamiento y cierre del acta, como redactado en los instantes en que los sucesos están ocurriendo. Aunque básicamente coincide con el que ya fue publicado a partir del traslado que se presentó al parlamento, por sus ligeras variantes no exentas de interés, damos aquí su reproducción [Fig. 1] y su trascripción:

Senyor, nosaltres (tachado: XII) elets per la cort de Catalunya som assi davant la vostre magestat, humilment suplicant vos queus placia (tachado: vullats) fer dues coses les quals son e redunden en sobirana utilitat de la cosa publique de tots vostres regnes e terres. La primera, quels vullats exortar de haver entre si amor, pau e concordia per ço que Deus los vulla en tot be conservar. La segona queus placia (tachado: vullats) de present (tachado: despendre) manar a tots los dits regnes e terres vostres que per tots lurs poders e forçes façen per tal forma e manera que la successio dels dits vostres regnes e terres (tachado: perveynen a aquell) apres opte vostre perveynen a aquell que per justicia deura pervenir com aço sia molt plasent a Deus e sobiranament profitos a tota la cosa publique e molt honorable e pertinent a vostra reyal dignitat. Et hiis dictis, addens etiam dictus Ferrarius verbis per eum jam dictis [interlineado: per eum prolatis, cum dictus dominus rex nullum tunc dedisset ad predicta responsum (?)], dixit hec verba vel similia in effectu: Senyor, plau vos quels (tachado: dits) regnes (tachado: et) e terres vostras sien e pervinguen a aquell al qual pertanguen per justicia? Et dictus dominus rex tunc respondens dixit: Hoc. De quibus petiit dictus Ferrarius publicum fieri instrumentum per me notarium supradictum. Que fuerunt acta die et hora, loco et anno predicáis, presente me dicto prothonotario et notario ac pro testibus talibus.

Postea die sabbati XXXI ${ }^{a}$ madii anno predicto, circa horam tertie dicti diey, dictus Ferrarius de Gualbes (tachado: existens) constitutus personaliter ante presenciam dicti domini regis [interlineado: cum aliis de dicta curia cum eo electis dixit] in presencia mei dicti notari et testium suscriptorum (tachado: dixit in effectum), reducens ad memoriam dicto domino regi verba per eum supra dicto domino regis per eum jam prolata, dixit: Senyor, plau vos quels dits vostres regnes e terres sien e pervinguen a aquell al qual pertanguen per justicia e quen sia feta carta publica? Dictus dominus rex respondens dixit: Och. Et cum etiam ego dictus notarius interrogasset dictum dominum de predictis et si (tachado: et) erat talis eius intentis,

56.- "Hoc est translatum fideliter sumptum a nota cuiusdam instrumenti inferius inseri quod fuit per me Raymundum de Cumbis, olim protonotarium et notarium subscriptum, receptum die et anno in eo contentis, scripta et continuata in protocollo sive capibrevio notularum mei dicti notarii et in fine cuius note major pars testium qui ad confeccionem dicti instrumenti presentes fuerunt se eorum manibus subscripserint. Cuiusquidem note sive instrumenti et etiam testium qui se subscripserunt tenor est talis". 
ÚLTIMAS VOLUNTADES DE MARTÍN I EL HUMANO (30 Y 31 DE MAYO DE 1410)

videlicet, quod regna et terras suas predictas sunt et perveniant illi cui de iure pertineant, (tachado: respondit: och. De quibus) et quod inde fiat publicum instrumentum, respondit och. De quibus omnibus dictus Ferrarius, nomine suo et aliorum ut dixit de Curia supradicta, petiit et requisivit fieri instrumentum per me notario ac testibus supradictis.

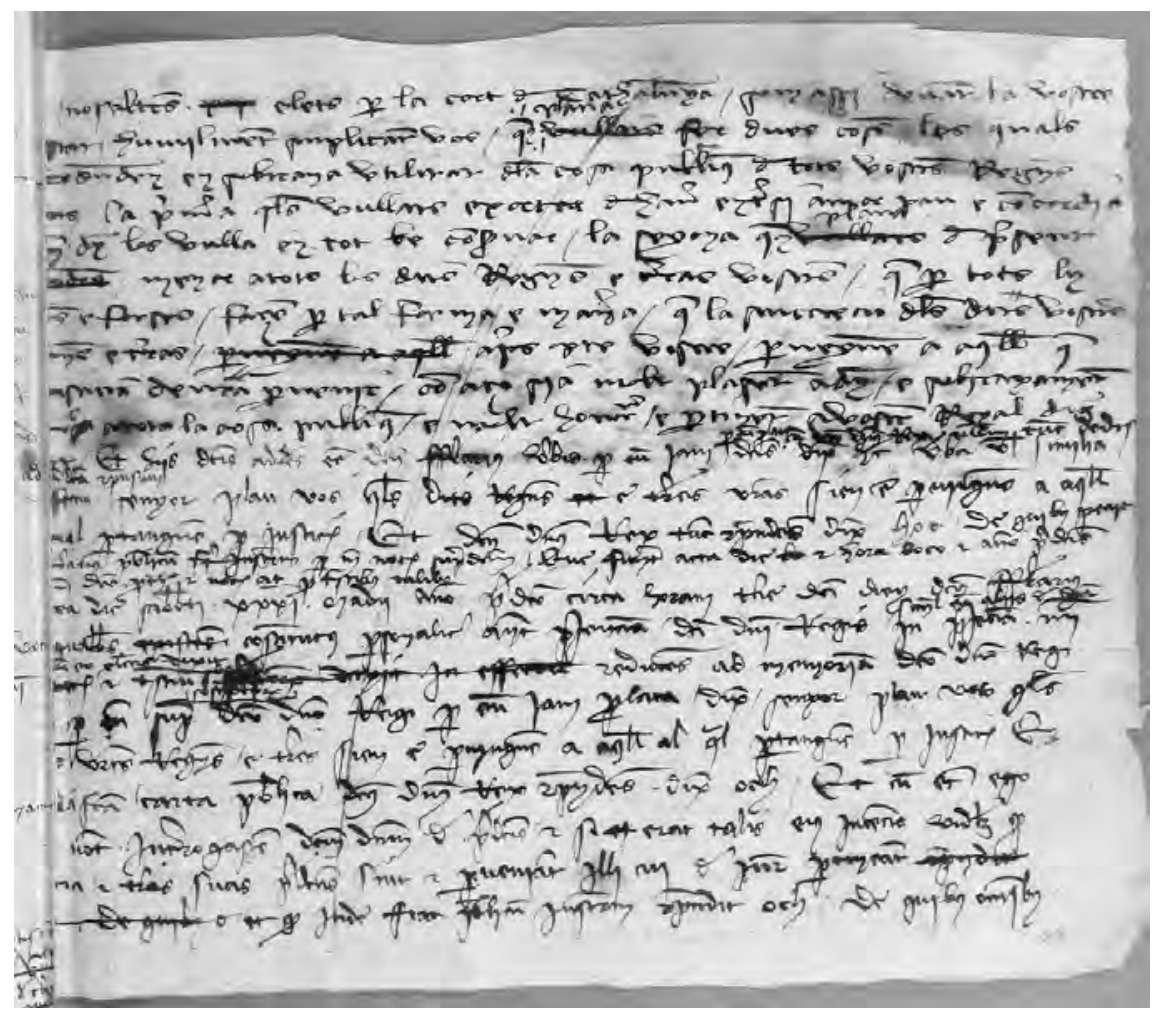

Fig. 1. ACA, Generalidad, vol. 962, f. 23r de la segunda numeración inferior.

A este texto sigue el borrador del protocolo del instrumento notarial de 29 de julio de 1411, tal como se presentó ante el parlamento catalán el 22 de octubre de $1411^{57}$, con numerosas enmiendas, tachaduras e intelineados, que

57.- "Pateat universi quod die veneris que computabatur $\mathrm{XXX}^{\mathrm{a}}$ madii anno a nativitate Domini $\mathrm{M}^{\circ} \mathrm{CCCC}^{\circ}$ decimo, circa undecimam horam noctis dicti diey, existente coram serenissimo domino Martino Dei gratia rege Aragonum, Sicilie, Valencia, Majoricarum, Sardinie et Corsice, comite Barchinone, duce Athenarum et Neopatrie ac etiam comite Rossilionis et Ceritanie, Ferrario de Gualbis, consiliario hoc anno ac cive Barchinone, ad subscripta, ut dixit, per curiam generalem quam dictus dominus rex de presenti catalanis celebrat in civitate predicta, simul cum aliis de dicta curia ibidem cum eo 
en sustancia no alteran su redacción. Pero en el cuaderno de notas del protonotario Sescomes, además de la minuta original, se encuentra un ejemplar en limpio de este traslado, que constituye la pieza núm. [27], la que lo cierra. El texto de esta pieza corresponde fielmente (salvo diferencias mínimas, como "plàcia-vos" por "plàcie-vos") al que ya conocemos, pero la sucesión de grafías indica los pasos en su elaboración. En una primera fase, se redactó el acta original (desde el principio "Pateat universis quod die veneris..." hasta la segunda respuesta del rey del día 31, "de quibus omnibus"), con una cuidada letra de molde librario. Este texto sufrió todavía algunas modificaciones que debieron ser coetáneas a esta primera redacción, realizadas por el protonotario Sescomes: se interlineó la intitulación del rey, que se había abreviado; se hicieron algunas correcciones menores (por ejemplo, en la abreviatura de la palabra "protonotario"); y, sobre todo, se añadió en el margen inferior del folio la cláusula notarial de cierre al acta del día 30 de mayo y la suscripción de los testigos presentes ese día ${ }^{58}$ (aunque al guillotinar el volumen para su encuadernación se perdió parte del texto). Corregido por el protonotario, al acta se añadió además la cláusula notarial de cierre, la suscripción de los testigos del día 31 y los signos de dos notarios de Barcelona, Bernat Mateu y Antoni Brocard. Con esto, el instrumento público al cual el rey dio su consentimiento quedó redactado en forma. Posteriormente, se añadió al margen superior del folio la fórmula de anuncio del traslado notarial hecha por Sescomes ("Hoc est traslatum...tenor talis est"), el signo y suscripción de Genís Almogàver, regente la veguería de Barcelona, hecho el 29 de julio de 1411; y finalmente, de su mano, el signo de Sescomes, cerrando todo el documento, que fue el presentado ante el parlamento catalán en la sesión de 22 de octubre de 1411. Así pues, el cuaderno de Sescomes nos proporciona, en relación con este importante suceso, la minuta, el acta pública original y la nota de su traslado. No se puede pedir más.

Volvamos a la minuta original de la última voluntad del rey Martín I, señalado con el número [15], que es el documento más interesante por ser el

presentibus electo, in presentia mei Raymundi de Cumbis, prothonotarii dicti domini regis et notarii subscripti ac testium subscriptorum, dixit coram dicto domino rege, existente infirmo, in suo tamen sensu cum loquela, in quadam camera monasterii Vallisdomicelli vocata de la Abadesa, hec verba vel similia in effectu."

58.- "De quibus omnibus petiit et requisivit dictus Ferrarius publicum fieri instrumentum per me prothonotarium et notarium supradictum. Que fuerunt acta die, hora, loco et anno predicto, presente me dicto prothonotario et notario ac pro testibus reverendo in Christo patre Ludovico, episcopo Majoricensi; nobilibus Geraldo Alemanni de Cervilione, gubernatore Catalonie, Rogerio de Montechateno, gubernatore regni Majoricarum, camarlengis; Petro de Cervilione, majordomo, Raymundo de Sanctominiato, camarerio, militibus; Francisco d'Aranda, donato Portaceli, consiliariis dicti domini regis, et Ludovico Aguilo, domicello, ac nobili Guillermo Raymundo de Montechateno, coperio jamdicti domini regis." 
más inmediato a los acontecimientos. Hay una variación de gran significado histórico. Según esta minuta, Gualbes, tras hacer sus dos primeras preguntas al rey, repitió la segunda con otra fórmula, pues el rey no contestaba ("cum dictus dominus rex nullum tunc dedisset ad predicta responsum"), expresión que desapareció de la versión final, que fue la presentada al Parlamento. Esto nos hace más comprensible la escena, que Soldevila no entendió con razón, pues nos muestra al monarca actuando según su costumbre, al permanecer como adormilado y en silencio unos instantes antes de pronunciarse sobre una cuestión delicada, lo que desorientaba a sus interlocutores, como hizo con la embajada que le propuso designar a Luis de Calabria como sucesor, o como había hecho poco antes con la madre del conde de Urgel en aquel mismo lecho de muerte ${ }^{59}$. Tan notable como este detalle resulta el hecho de que, en esta misma pieza de papel, al dorso e invertidas, están escritas, con otra tinta aunque quizá de la misma mano, tres columnas de nombres (algunos de ellos con una cruz al margen izquierdo), la del medio y la derecha con encabezamientos [Fig. 2]. Las listas son como siguen:






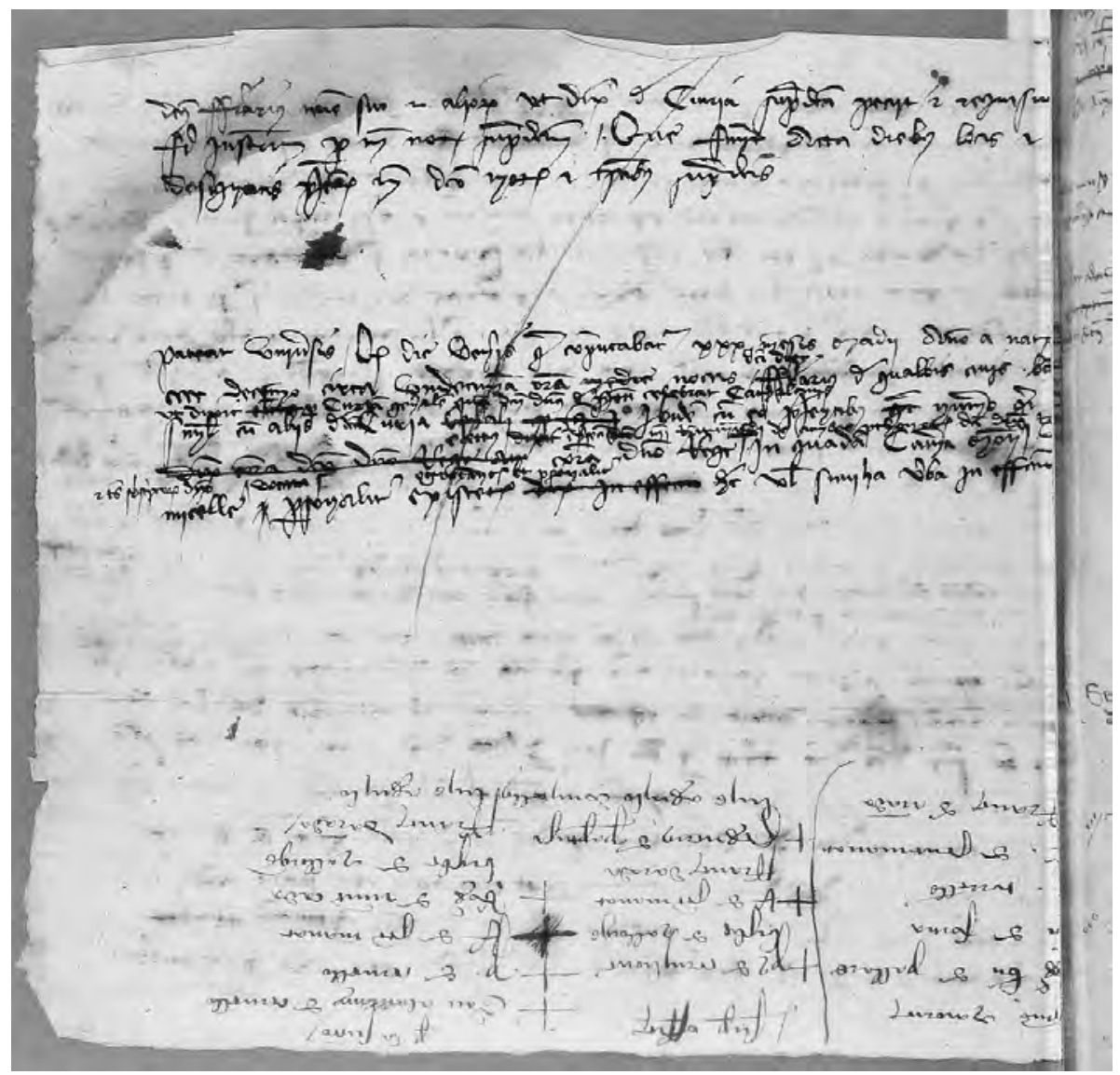

Fig. 2. ACA, Generalidad, vol. 962, f. 23v de la segunda numeración inferior.

La tercera columna se corresponde con los testigos que suscribieron el acta notarial de la última voluntad del rey Martín en la noche del 30 de mayo de 1410, a falta de Guillem Ramon de Moncada, de la rama catalana de los señores de la baronía de Aitona y copero del rey, que precisamente firmó el último, razón por la cual quizá ya no fue incluido en esta lista que provisionalmente debió redactar el protonotario casi al tiempo de tomar esta nota. La cruz, claramente añadida en un momento posterior al margen izquierdo de esta columna, debió responder a la primera intención del notario Sescomes de ir señalando a los que también firmaron el acta del día 31. De ahí precisamente el error de incluir a Ramon de Sentmenat y tachar después su cruz, pues ya no 
firma como testigo el día 31, ni tampoco Roger de Moncada ni el obispo de Mallorca, aunque sí Francisco de Aranda y Luis Aguiló. Estas vacilaciones, en una lista que no deja de ser un mero recordatorio del protonotario para su uso personal, son comprensibles en momentos de gran agitación como los que debían ser aquellos instantes en las habitaciones del rey, con entradas y salidas repentinas y continuas de los grandes personajes. Pero el protonotario consiguió al menos a cinco de los ochos testigos que el día anterior habían suscrito el acta ${ }^{60}$. La veracidad de este papel la confirma el hecho de que el traslado notarial de 29 de julio de 1411 se refiera a estas listas de testigos puestas de modo informal al pie de la nota que contiene el acta de la última voluntad del rey Martín I ("Hoc est translatum...tenor est talis") ${ }^{61}$. Adviértase que Sescomes especifica que la nota fue firmada por la mayor parte ("major pars testium") pero no la totalidad de los testigos (que sin duda no eran todas las personas que asistieron) presentes en la escena.

El hallazgo de esta pieza de papel desmonta las modernas acusaciones de falsedad o manipulación que se dirigieron contra el acta de la última voluntad del rey Martín. Ciertamente, alguna fórmula y las preguntas que se realizaron según consta en las notas de Sescomes difieren en cuestiones de detalle respecto de la redacción en limpio del acta, porque fueron más directas y menos retóricas. Creemos que las diferencias obedecen más bien al deseo del protonotario de pulir estilísticamente el instrumento final, cuya publicidad y trascendencia preveía, por mero prurito profesional. Pero, además, el acta nos informa de que, junto con la cuestión de "la successió", como se indica claramente en las listas de testigos, en aquella escena se dilucidó al menos otro asunto, que se denomina "super officis". ¿En que consistía?

Nada ha dicho la historiografía sobre este punto, que es de una importancia extraodinaria, como lo demuestra el hecho de que el monarca y su entorno más inmedito trataran de resolverlo en sus últimas horas de vida. Lo podemos conocer ahora, gracias al cuaderno de notas del protonotario Sescomes, rompiendo así la imagen creada de que, en su lecho de muerte, el rey Martín se limitó a contestar a una pregunta sobre la sucesión, casi agónicamente — si es que lo que realmente se entendió como un "sî" no fue un mero estertor, como se ha llegado a afirmar.

En efecto, la cuestión "super officis" a la que se alude en las notas de Sescomes, refiriéndose a los testigos que habían de suscribir algún tipo de acta,

60.- F. Soldevila, El Compromís de Casp, pp. 48-49 da otra explicación a la falta de las firmas del obispo y gobernador de Mallorca y lo atribuye a su "urgelismo", que les hace resistirse a la maniobra conspirativa de Violant de Bar, la cual alienta toda la intriga.

61.- Cfr. nota 56. 
se entiende a la vista del núm. [16] de las piezas incluidas en este cuaderno, en el folio siguiente (f. 24r). Las notas se repiten, primero como borradores con emiendas y tachaduras en la mitad superior del folio, y después en limpio, en la mitad inferior de la misma cara de ese folio, y cuya trascripción - la de las notas en limpio- es como sigue:

[a] Senyor, placieus que donets poder a la Cort de Cathalunya que en cas que vos deffallissets, ço que Deus no vulla, ells puxen elegir algunes notables persones qui hagen poder de regir e governar lo dit Principat axi com si per la vostra persona eren elets (tachado en el borrador: fins, senyor, que fos vist per justicia vist — sic - dit principat la successio del dit principat e dels regnes e terras vostres a quis pertanyeren per justicia). Et dictus dominus Rex, respondens, dixit no. Etc.

[b] No. Mossen Roger, no entenats que so que dehim digam per que vosaltres abdos perdats vostres Governacions ne encara los officials trienals.

[c] Plau a vos, senyor, quels dits Governadors e altres officials triennals remanguen en lurs officis.

[d] Et dictus dominus Rex respondendo (sic) dixit hoc.

Estamos ante algunas palabras que salieron de la boca del monarca moribundo, que no se limitó a responder afirmativamente a todas las preguntas que se le hicieron en aquellos duros momentos, sino que, en primer lugar, se negó a la que tenía un alto contenido político que iba en detrimento de la autoridad real, como la propuesta de dar poder a las Cortes de Cataluña para elegir personas que gobernaran el Principado, contenida en el párrafo [a]. Hizo después observaciones de su propia boca, dirigidas a los gobernadores de Cataluña y Mallorca, que estaban presentes, en el párrafo [b]. Y aceptó por último la propuesta modificada que expresaba con precisión su voluntad, en los párrafos [c] y [d].

De las notas de Sescomes conteniendo este acta, parece que no se levantó un instrumento notarial en forma, ni nadie se interesó por la voluntad del rey en este asunto, pero parte de los episodios del Interregno se explican a la luz de esta manifestación del soberano: la razón por la cual los gobernadores y otros oficiales trienales - que tuvieron tanta importancia en el desarrollo de los acontecimientos - continuaron en sus puestos, o la explicación de por qué las Cortes no pudieron sustituir el gobierno real que quedaba suspendido por la muerte del soberano mediante el nombramiento de una regencia sujeta al parlamento (lo que en realidad hubiera significado suplantar el poder real), lo que obligó a buscar otras fórmulas jurídicas más complejas para resolver la situación creada sin detrimento del poder monárquico. Esta declaración de la voluntad real, junto con el acta sobre la sucesión de los reinos, parece formar parte de una estrategia de Martín I, que se entiende a 
la vista de otras manifestaciones y documentos de los que el protonotario Sescomes tomó nota.

No es la única sorpresa que nos depara este folio 24. Basta con girarlo, para encontrarnos con más información inédita de una importancia extraordinaria. ¿Qué encontramos allí? Dos listas de nombres y el borrador de otro texto. La primera lista corresponde, como se indica junto a la llave que los agrupa, a "Los elets per la Cort de Cathalunya". Los nombres son los que siguen:
Mossen l'abat de Ripoll.
Mossen Johan Nadal.
Mossen Ferrer d'en Pujol.
Mossen lo prior de Tortosa.
Roger. Bn. de Pallars.
Mossen Bernat de Fortia.
Mossen Berenguer d'Olms.
Mossen Matheu Cardona.
Ferrer de Gualbes.
Ffrancesch Marquet.
Micer Miquel de Navers.
Bn. Mongat.

La segunda lista aparece bajo el título: "Los XII consellers", con estos nombres:

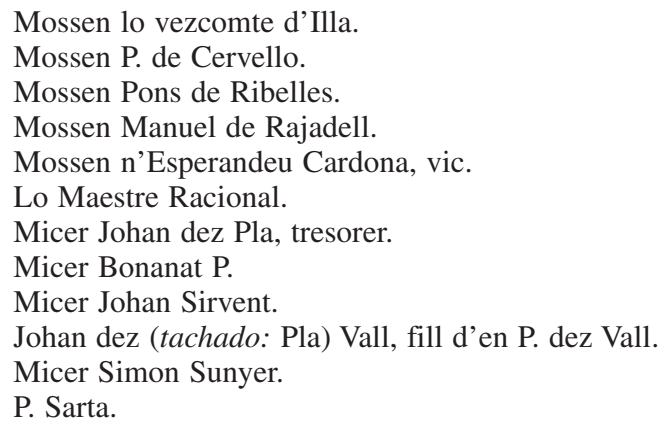

Lo que nos proporcionan estas dos listas, pues, es la relación de miembros de una de las habituales comisiones mixtas de las Cortes, compuesta por representantes de los tres brazos del parlamento y por un número equivalente de consejeros reales, que se nombraban para las cuestiones más delicadas, como parece ser la visita que se hizo al monarca para sus últimos actos. La primera lista incluye los nombres de los electos de los estamentos que acompañaron a Ferrer de Gualbes, tal como se menciona en el acta sobre la sucesión del rey Martín, y cuyo número, recuérdese, aparecía en las notas 
de Sescomes, aunque se eliminó en su redacción final. Se despeja así una de las dudas e incovenientes, alegados por Girona y Soldevila, respecto al desconocimiento que teníamos de los miembros de esta comisión en la que, ahora lo sabemos, no interviene ningún obispo que pudiera reclamar para sî la preeminencia protocolaria, por lo que bien pudo corresponder a Gualbes la función de portavoz de la comisión, tal y como se recoge en el acta tantas veces citada. Tampoco obsta el que no se encuentre en el proceso de Cortes el nombramiento de esta comisión. El propio Soldevila acepta que este era un hecho corriente en la mecánica parlamentaria de la época, y que el acuerdo de enviar esta comisión ante el rey y su nombramiento pudo hacerse sin que conste en el proceso, e incluso que esta decisión pudo tomarse si no a espaldas de las Cortes, sí fuera de las sesiones, que eran muy poco frecuentadas ${ }^{62}$. Sin contar al regente de la cancillería, Bonanat Pérez, que presidía la sesión, solo hubo 20 asistentes el día 29 de mayo y 14 el día $30^{63}$.

Conocemos las asistencias de los miembros de esta comisión de 24 personas (doce electos y doce consejeros) a las sesiones de las Cortes durante el mes de mayo ${ }^{64}$. A la del día 29, asistieron por los eclesiásticos: Berenguer de Rajadell, abad de Ripoll; Joan Natal (como procurador del arzobispo de Tarragona), Ferrer d'en Pujol (procurador del obispo de Barcelona) y Joan Ciurana (prior de Tortosa, como procurador de la iglesia de esa diócesis). Los cuatro integraban la comisión y habían representado al estamento eclesiástico a lo largo de las sesiones del mes de mayo. También asistieron ese día los procuradores de los abades de Montserrat y Santa María d'Arlés. Por los nobles acudieron Berenguer d'Olms, Mateu Cardona (ambos en la comisión) y Ramon de Blanes, que era mayordomo del rey. Tanto Olms como Cardona parecen actuar como representantes de los caballeros en estas sesiones del mes de mayo, meramente formales, pues se limitan a prorrogarse. El mismo papel parecen desempeñar Roger Bernat de Pallars y Bernat de Fortià respecto de los nobles. En el extremo opuesto, ninguno de los donceles que habitualmente asistieron en esas semanas (especialmente, Berenguer de Caxas) se integra en la comisión, pues este grado inferior del brazo militar pierde su representación a favor de los mayores del estamento (nobles y caballeros). Por último, Ferrer de Gualbes, Francesc Marquet y Joan dez Vall asisten como síndicos por Barcelona, junto con otros representantes de las ciudades y villas reales, como Miquel de Navers y Simon Sunyer (síndicos de Lérida), Berenguer Mongat (síndico de Vilafranca de Conflent) y Pere Sarta, (síndico

62.- F. Soldevila, El Compromís de Casp, pp. 40 y ss.

63.- Cortes, t. VI, pp. 442-444.

64.- Cortes, t. VI, pp. 432-444. 
de Manresa). Ahora bien, algunos de estos representantes de las villas reales se incorporan a la comisión de 24 personas por la parte del rey, en tanto que "consejeros", a fin de hacer paritaria esta comisión, y aprovechándose del hecho de que algunos de ellos son doctores en derecho, como Simon Sunyer o Joan Sirvent, quien en otras sesiones había acudido por el brazo eclesiástico como procurador de la iglesia de Elna. Por parte de los consejeros, participan lo que podríamos denominar el "núcleo" del Consejo real ${ }^{65}$ : Pere de Fenollet, vizconde de Illa y Canet, camarlengo del rey desde 1399 y hombre de gran confianza del monarca; Pere de Cervelló, copero de Martín como infante en 1387 y su mayordomo desde 1396; Esperandéu Cardona, vicecanciller; Pere Savall, maestre racional; Joan Dezplà, tesorero; y Bonanat Pérez, regente la cancillería. Como hemos visto, la comisión de consejeros reales fue completada con los caballeros Pons de Ribelles y Manuel de Rajadell ${ }^{66}$, con dos doctores en derecho (Joan Sirvent y Simon Sunyer) y con dos síndicos populares (Pere Sarta y Joan dez Vall).

Regresemos de nuevo a la pieza núm. [16]. ¿De cuándo datan todas estas notas: de la noche del 30 de mayo o de la mañana del 31 ? No aparece ninguna fecha, pero ciertos extremos de este papel permiten aventurar algunas suposiciones. En este mismo folio, pero con la escritura en sentido longitudinal, hay otro texto que transcribimos:

Considerants que estants en aquest humanal cors viuvim (sic) a temps per divinal permissio en la terra, molt mes devem desijar obtenir lo Regne celestial ab los sants, e que tant pus fortment devem per tembre la mort (tachado: inevitable) sobtosa quant la certitu (sic) no dubtosa de la mort inevitabla (sic) a nos se acosta. Emperamor da (cortado al fin de la línea) d'aço (sic) sabents al regne celestial no podem pervenir tro quel (tachado: lo) nostre cors haja complida la ley nat- (cortado al fin de la línea) e (tachado: mo) per mort sia tornat en la terra de la qual som certs que es estat produhit, renovellador apres per gracia, per anticipada cautela disposam pervenir a disposicio testamentaria mentre son en tranquillitat de (tachado: pensa raho) pensa e ab ferma raho, e de la abtesa del temps se offer oportuna. Emperamor d'aço, invocada la gracia del Sant Sperit e demanada homilment venia de nostres peccats, revocants expressament e de certa ciencia tots altres e quals sevol (sic) testaments e codicils si

65.- Sobre estos personajes, M. T. Ferrer, “El Consell”, pp. 175-190.

66.- Manuel de Rajadell fue armado caballero por el rey Martín durante la ceremonia de su coronación en 1399 (J. Zurita, Anales, X, 69). En junio de 1410 era veguer del condado de Ampurias y administraba las rentas de la reina Margarita, de la cual fue abogado ante el Parlamento de Cataluña (Cortes, t. VII, Madrid, 1903, pp. 230-231) y de quien continuaba siendo camarlengo en 1412. Con la llegada de la nueva dinastía, se retiró y buscó un beneficio eclesiástico (Jaume Torró Torrent, "Només hi ha un Joan Martorell documentat amb el nom de Joanot. (Resposta i correcció a Agustín Rubio Vela amb unes notes sobre Manuel de Rajadell)", Tirant, 15 (2012), pp. 22-23). 
alguns per nos ne son estats fets o seran atrobats, salves e exceptades les coses deius afirmades, fem e ordenam aquest nostre testament en lo qual la nostra perfeta volentat e disposició de nostres regnes e terres puxe esser atrobada.

Aquí se interrumpe el texto. No se corresponde con el testamento que Martín I otorgó el 2 de diciembre de 1407 ni conocemos que se haya extendido ningún instrumento o declaración suya en estos términos. Lo que nos indica este documento inconcluso es que, en algún momento durante la agonía del soberano, se preparó el borrador de un testamento nuncupativo, pergeñado por los consejeros y electos que figuran en el mismo folio, mediante el cual el soberano manifestara claramente su voluntad respecto de la sucesión de los reinos. Este borrador no debió obtener el respaldo o bien de todos los consejeros que rodeaban al moribundo o bien del propio rey. Pero en el folio siguiente, el 25r, que corresponde a la pieza núm. [17] del cuaderno de Sescomes, hay otro documento que aporta alguna luz al asunto. Este mismo documento está copiado en la pieza núm. [5], con algunas pequeñas diferencias. Y su importancia también es extraordinaria, por lo que damos aquí la trascripción del núm. [17], con sus variantes respecto a la pieza núm. [5] indicadas en nota:

Pateat universis quod die veneris qua computabatur tricesima madii anno a nativitate Domini millesimo $\mathrm{CCCC}^{\circ}$ decimo $^{67}$, undecimam oram ${ }^{68}$ noctis eiusdem die, serenissimo domino Martino ${ }^{69}$, Dei gracia rege Aragonum, Sicilie ${ }^{70}$, Valencia, Mairoicarum, Sardinie, Corsice, comite Barchinone, duce Athenarum et Neopatrie ac etiam comite Rossilionis et Ceritanie (tachado: existente) personaliter existente in quadam camera monasterio Vallis Domicelle vocata de la Abadessa ${ }^{71}$, corporali detento infirmitate, de qua mortis periculum pertimebat, in suo tamen sensu cum firma loquela ${ }^{72}$, cum honorabilis et religiosus Ffranciscus ${ }^{73}$ d'Aranda, donatus (tachado: Po) monasterii de Portaceli dixisset dicto domino Regis (sic) haec verba vel similia in effectu: Senyor, per vostra senyoria fon feyt et fermat molt ha testament en lo qual fahiets hereu ${ }^{74}$ lo senyor rey ${ }^{75}$ vostre fill, ${ }^{76}$ plau

67.- En núm. 5: "quadringentesimo decimo".

68.- En núm. 5: "circa undecimam horam".

69.- En núm. 5: "serenisimo ac magnifico principe et domino, domino Martino".

70.- En núm. 5: "Sicilie etcetera".

71.- En núm. 5: "personaliter existente in quadam camera vocata de la Abadessa monasterii Vallis Domicelle territori Barchinone".

72.- En núm. 5: "cum firma loquela et memoria".

73.- En núm. 5: "frater Ffranciscus".

74.- En núm. 5: "hereu universal".

75.- En núm. 5: "de Sicilia".

76.- En núm. 5: "a qual Deus do sancta gloria". 
vos, senyor, confirmar lo dit testament axi que en lexes e altres coses romanga en sa plena força e valor. Et dictus (tachado: $\mathrm{R}$ ) dominus Rex respondens dixit hoc. Et incontinenti reverendus dominus Ludovicus Maioricarum Episcopus ${ }^{77}$, qui presens ibi ${ }^{78}$ erat, dixit haec verba vel similia in effectu: Senyor, (tachado: vos havets feta donacio a la aquesta confirmacio (sic) que fets seria prejudicial a la donacio que havets feta a la senyora Regina) placieus que aquesta confirmacio que fets sia feta sens prejudici de la donacio per vos feta a la senyora Regina, plau vos, senyor (interlineado: axi). Qui respondens, dixit hoc. Et ex tunc ego dictus notarius et prothonotarius dixi dicto domino Regi haec verba: donchs (sic) senyor, (tachado: vos confirmats) a vos plau que la dita confirmacio sia feta sens perjudici de la donacio per vos feta a la senyora Regina (interlineado: e que de tot sia feta carta publica). Et dictus dominus Rex respondens dixit och $(s i c)^{79}$. Et sic confirmavit testamentum predictum ita quod in legatis et aliis in eo contentis stet et remaneat in suo pleno robore et valore sine tamen prejudicio donacionis per eum facte dominis Regine predicte. De quibus omnibus ${ }^{80}$ fuit factum de voluntate dicti domini Regis presens publicum instrumentum in testimonium omnium premissorum ${ }^{81}$. Que fuit acta die, loco et anno predictis, presente me dicto notario et prothonotario et presentibus testibus etcetera ${ }^{82}$.

La pieza núm. [17] parece ser la minuta original, con sus tachaduras y enmiendas, tomada en presencia del monarca, mientras que, en vista de su redacción y de las correcciones introducidas en el texto, la núm. [5] es ya una versión en limpio que pudiera considerarse el acta pública a la cual da su consentimiento el rey, aunque no sea todavía la definitiva, porque, a falta de las suscripciones notariales y a juzgar por las apostillas añadidas al final del documento, tal y como se procedió con el acta sobre la sucesión de los reinos, se somete todavía a la revisión de alguien cuya identidad desconocemos. La letra de este revisor último no parece que se corresponda con la de Esperandéu Cardona, vicecanciller del rey, tal como la conocemos por sus notas autógrafas incluidas en la pieza núm. [6], en el folio que sigue a esta versión, cuyo texto es muy breve y casi desaparecida la tinta por efecto de la humedad. Su lectura es dificultosa pero damos aquí su trascripción:

77.- En núm. 5: "Et incontinenti reverendus in Christo pater Ludovicus miseracione divina Maioricarum Episcopus".

78.- En núm. 5: "ibidem".

79.- En núm. 5: "hoc".

80.- En núm. 5: "et singulis".

81.- En núm. 5: "in testimonium premissorum".

82.- En núm. 5: "et presentibus etiam”. Siguen dos líneas de apostillas de otra mano coetánea, con el texto: "Videtur michi congruas clausulas et bene composita dumtamen prima firma regis vel çeda sufficiat". 


\begin{abstract}
Quare ego Esperandeus Cardona olim vicecancellarius domini regis non vidi abreviaturam seu scedam huius instrumenti $(1,5 \mathrm{~cm}$ ilegible $)$ super substancia instrumenti set videtur michi quod atenta substantia [hic] expressa instrumentum istud ( $2 \mathrm{~cm}$ ilegibles) bonas clausulas et bonam expressivam. Sperandeus.
\end{abstract}

Esperandéu Cardona fue vicecanciller de 1389 a 1396 y otra vez desde $1403^{83}$. Martín I lo había designado como uno de sus albaceas en su testamento de 2 de diciembre de 1407, que fue recibido precisamente por Ramon Sescomes ${ }^{84}$. De mano de Cardona parecen ser una parte de las otras apostillas que salpican los instrumentos que se incluyen en el cuaderno de notas de Sescomes. No se puede garantizar que esta apostilla se refiera a esta acta de la voluntad del rey Martín confirmando su testamento, aunque sea la interpretación más probable, pero sí nos permite concluir que Esperandéu Cardona conocía los instrumentos jurídicos que se elaboraron en la cámara real durante la noche del 30 y la mañana del 31 de mayo de 1410 .

Por otro lado, con solo el análisis grafológico, es inseguro atribuir a individuos concretos estos documentos, notas y glosas. La apostilla que figura al pie de la pieza núm. [17] quizá sea obra del propio Sescomes, porque algunos rasgos coinciden con su escritura, como se puede deducir de la suscripción hecha de su mano al final del traslado del acta con la voluntad del rey Martín I sobre la sucesión, núm. [27] del cuaderno de Sescomes, tal como hemos visto. En cualquier caso, lo que nos indican estas apostillas - tanto la que viene al pie del núm. [17] como la núm. [6] y otras- es que los juristas del círculo real más inmediato (Sescomes y Esperandéu Cardona, como mínimo, que habían intervenido en la redacción del testamento del monarca) revisaron el contenido de estos instrumentos sin encontrar reparos.

Ahora bien, sabemos que al final de la minuta del acta sobre la sucesión de los reinos (pieza núm. [15]) se relacionaron tres listas de nombres, la primera sin título, y las otras dos bajo los encabezamientos "Per la successió" y "Super officis", que se corresponden con los testigos que suscribieron dos de las sucesivas actas que se prepararon durante la noche del día 30 de mayo. Atendiendo a que en aquellas horas se realizaron tres manifestaciones de voluntad real diferentes (la relativa a la sucesión de los reinos, cuyo portavoz fue Ferrer de Gualbes; la de los oficios trienales, y la de la confirmación del testamento), parece que esta primera columna sin título contenga los testigos que debían suscribir el acta de confirmación del testamento de

83.- J. Trenchs-A. Ma Aragó, "Las cancillerías", p. 56.

84.- Antoni Udina i Abelló, Els testaments dels comtes de Barcelona i dels reis de la Corona d'Aragó. De Guifré Borrell a Joan II, Barcelona, 2001, pp. 369-382. 
Martín I ("Episcopus Maioricarum; Roger Bn. de Pallars; Bn. de Fortia; R. Torrelles; R. de Sentmanat; Ffrancesc de Aranda"), cuyos portavoces fueron, precisamente, el obispo de Mallorca y Francisco de Aranda, y en el cual está, significativamente, Ramon de Torrelles, hermano de Pere de Torrelles, tutor de Federico de Aragón, más dos caballeros de la comisión de electos de las Cortes catalanas (Roger de Pallars y Bernat de Fortià). En este caso, se respetaron las precedencias protocolarias (cuya infracción se ha esgrimido como un argumento - no muy fundamentado, en nuestra opinión- para descalificar el acta hasta ahora conocida), pues fue el obispo de Mallorca quien tomó la palabra.

Fijemos ahora nuestra atención en la pieza núm. [17], porque es de una importancia capital. En primer lugar nos informa, como ya ocurrió sobre el acta relativa a los oficios trienales, que el rey manifestó durante sus últimas horas su voluntad respecto a cuestiones vitales bajo una misma fórmula y procedimiento, que se repite, esto es, accediendo o negando a preguntas que se le realizan, y dando su consentimiento para que se levante acta pública de su voluntad. En este caso, el rey se ratifica en su testamento de 2 de diciembre de 1407, que afecta en primer lugar a las mandas y legados que allí hizo, sin perjudicar por ello a la reina Margarita, con la cual se había casado posteriormente y por tanto podía quedar excluida de la herencia. Pero con esta declaración, el rey sabía que confirmaba también la condición de heredero universal de sus reinos a favor de su difunto hijo Martín el Joven y de sus descendientes, tal como lo establecía en la última clausula, sustituyéndolo en caso de muerte por su hijo varón primogénito legítimo, nacido de legítimo y carnal matrimonio, sustituyendo a su vez a este por cualquier otro de los hijos varones legítimos de Martín el Joven, procreado de carnal matrimonio, por orden de nacimiento ${ }^{85}$. En este caso parecería que el rey pensara que pudiera incluirse a Federico una vez legitimado ${ }^{86}$. Pero, ¿con qué alcance?

\section{Donación de Sicilia a Federico de Aragón}

Sobre el nieto del rey tratan otros dos documentos fundamentales de este interesantísimo protocolo de Sescomes. Son los que hemos señalado como núm. [9] y núm. [12]. El primero de ellos, [núm. 9], lleva por título: "Donacio regni Sicilie facta Egregio Ffrederico". Por tratarse de un documento inédito, damos aquí su trascripción:

85.- A. Udina, Els testaments, pp. 369-382.

86.- Es la opinión de J. Zurita, Anales, X, 91. 
Ihesus. In nomine domini nostri Ihesu Xhristi et virginis Marie, matris sue. Pateat universis presentis seriem inspecturis quod nos Martinus, Dei gratia Rex Aragonum, Sicilie, Valencie, Maioricarum, Sardinie et Corsice, comes Barchinone, dux Athenarum et Neopatrie ac eciam comes Rossilionis et Ceritanie, erga vos, dilectissimum nobisque carissimum nepotem nostrum sive net egregium Ffredericum, filium naturalem illustris Martini regis Sicile ducisque Athenarum et Neopatrie, filii primogeniti et unigeniti nostri carissimi memorie recolende, ex ipso primogenito nostro tunc soluto et muliere quadam tunc soluta genitum, ac per santissimum in Christo patrem dominum dominum summum pontificem et nos legitimatum et abilitatum specialiter et nominatim ad succedendum in Regno insule Sicilie et insulis eidem adiacentibus infrascriptis, munificencie dexteram extendentes ac cupientes vos in primordalibus vestris auspicis vestreque infancie inicio florido premunire aliquali civili potencia quem Rex regum potentem edidit alti regalis sanguinis quo trahitis originem sublimitatis prospecta. Affectantes vos dictum Egregium nepotem nostrum sive net regio favore prosequi et ad regiam dignitatem honorabiliter attollere, insiguire ac eciam sublimare, gratis et certa ciencia (tachado: motu nostro proprio) affectu intimo ducti quem ad vos gerimus et (tachado: ac) spontanea voluntate, per nos et omnes heredes et sucesores nostros quoscumque donacione, scilicet, pura, perfecta, simplici ac irrevocabili que dicitur inter vivos prout de iure, constitucione, foro aut aliter quovismodo melius valere potest ac poterit in futurum ac illis eciam via, modo et forma quibus intencioni vestri dicti egregii Ffrederici et vestrorum melius valeat adaptari, damus et ex causa donacionis concedimus vobis dicto egregio Ffrederici, licet a nostri presencia absenti, et prothonotario nostro ac notario subscripto pro vobis ut infra patet stipulanti et vestris et quibus volueritis perpetuo, totum ab integro Regnum (tachado: Sicilie) insule Sicilie cum insulis eidem adiacentibus, civitatibus, villis, terris, castris, populacionibus, (añadido al margen, de otra mano: mero et mixto imperio ac gladis et animadversionis potestate) jurisdiccionibis, preheminenciis, gabellis, tractis, subvencionibus, juribis, relevi, solaciis et aliis redditibus, juribus et pertinenciis universis et singulis ad ipsum regnum et insula eidem adiacentes quomodocumque et qualitercumque spectantibus et spectare debentibus (añadido al margen, de otra mano: nil seu nullo excepto vel reservato nobis aut successoribus vel heredibus nostris). Exigentes et actollentes vos, dictum egregium Ffredericum, in regem et dominum dicti regni et insularum eidem adiacentium, sic quod deinde vos, memoratus egregius Ffredericus, et vestri intitulemini perpetuo et nominemini reges regni insulae Sicilie, et sitis dignitate et honoribus regalibus plenarie insigniti. Hanc itaque donacionem et ex causa donacionis concessionem facimus nos, dictus rex, per nos et nostros successores quoscumque vobis dicto egregio Ffrederico, nepote nostro sive net carisimo tanquam benemerito et condigno et vostris et quibus volueritis perpetuo, de toto ab integro dicto regno cum insulis eidem adiacentibus et aliis superius designatis prout melius, utilius, plenius et comodiosius ac perfecte intelligi sive dici possit et intencioni vestri adaptari ad omnem salvamentum et bonum et sanum intellectum vestri et vestrorum in predictis successorum. Et extrahimus de et cum presenti predicta omnia et singula 
quae vobis donamus de iure, dominio, proprietate et posse nostri et nostrorum et alterius cuiuscumque persone. Eademque omnia et singula in vestrum vestrorumque ius, dominium, possessionem et posse mittimus et transfferimus irrevocabiliter, pleno iure ad habendum, tenendum omnique tempore pacifice possidendum et ad omnem vestram vestrorumque voluntatem inde libere faciendam, sine contradiccione et impedimento nostri et nostrorum et alterius cuiuscumque persone. Promittendes tradere vobis aut tutori vestro vel balio aut cui volueritis loco vestri possessionem corporalem seu quasi predictorum omnium et singulorum que vobis donamus vel vos aut vestri, si volueritis, ex libera licentia et facultate plenaria quas in, de et cum presenti vobis conferimus quamque liceat nobis vel nostris revocare seu modo aliquo impedire alia, scilicet licentia seu mandato a nobis vel nostris minime expectato seu postulato possitis, et vobis ac vestris dictoque vestro tutori vel balio liceat per vos seu vestrum tutorem vel balium predictos aut procuratorem vel procuratores vestra et eorum propriis auctoritatibus quandocumque, scilicet et incontinenti cum vobis et eisdem placuerit ipsam possessionem corporalem seu quasi et alia pertinencia ad ipsum possessionem apprehendere, et aprehensa penes vos licite retinere. Nos enim integram donec ipsam possessionem vobis vel vestris predictis corporaliter et de facto tradiderimus vel vos aut vestri seu tutor vel balius vester aut procurator seu procuratores vestri eam apprehenderitis seu apprehenderint ut est dictum, constituimus et facemus nos predicta omnia (tachado: fuerit (?) de iure vel de facto aut alias de predicta) quae vobis supra donamus (tachado: tenemus seu possidere aut tenere censemur illud) pro vobis et vestro nomine (tachado: procuratorio) possidere seu quasi. Volentes et expresse consentientes quod virtute horum verborum et ex iuris disposicione ipsa possessio habeatur de presenti in vos et vestros pro traslata ac si per nos (tachado: a nobis personaliter) vobis seu vestris tutori vel balio seu procuratori aut procuratoribus realiter et de facto tradita extitisset. Et ex causa huiusmodi donacionis et alias damus, cedimus et mandamus vobis et vestris et quibus velitis omnia iura omnisque vices, voces et acciones reales et personales, mixtas, utiles et directas, ordinarias et extraordinarias et alias quascumque nobis competencia et competere debencia ac debentes in predictis omnibus et singulis que vobis supra donamus et concedimus et contra quascumque personas et res, ratione eorum et exercicium eciam nostrum dictarum accionum et iurium. Quibus possitis in iudicio et extra uti, agere et experiri quemadmodum nos possemus aut huiusmodi donacionem et iurium ac accionum, cessionem et eciam postea quandocumque. Nos enim, ponentes vos dictum egregium Ffredericum in locum et ius nostrum, facimus et constituimus vos et vestros in eisdem dominos et procuratores ut in rem vestram propriam ad faciendum inde vestras omnimodas voluntates. Salvo tamen semper onere, solucionis, census, debiti (interlineado, de otra mano: et fidelitatis) sacrosante Romane Ecclesie et ipsius ecclesie directo dominio a qua predictum regnum et supradicta omnia et singula que vobis supra donamus et concedimus, tenemus in feudum. Mandantes serie huius publici instrumenti quod vice epistole gerere volumus, in hac parte universis et singulis prelatis, comitibus, vicecomitibus, nobilibus, richis hominibus, militibus et generosis, capitaneis, castellanis et officialibus nostris 


\section{CARLOS LÓPEZ RODRÍGUEZ}

vel eorum locumtenentibus necnon quibusvis universitatibus, corporibus, collegiis et judeorum ac sarracenorum aliamis et singularibus earumdem ac aliis quibuscumque personis ad quas presentes pervenerint et pertineant (tachado: infrascripta) supradicta quod vos dictum Ffredericum et vestros pro eorum regibus et dominis naturalibus habeant et teneant vobisque et vestris pareant, respondeant et obediant in, de et super omnibus et singulis, in et de quibus nobis ante presentem donacionem debebant et tenebant respondere, parere ac eciam obedire ac pro eis vobis et vestris aut tutori seu balio, procuratori seu procuratoribus vestris homagium faciant et fidelitatis debitum juramentum. Nos enim cum dictum juramentum et homagium vobis aut dictis tutori vel balio, procuratori aut procuratoribus vestris prestiterint nunc pro tunc absolvimus eosdem omnes et singulos ab homagio, juramento et fidelitate et quavis alia obligacione quibus nobis astricti sunt pro predictis quod vobis dicto egregio Ffrederico et vestris donamus et concedimus vel alias quomodolibet obligati. Promittimus itaquod vobis dicto egregio Ffrederico licet a nostri presencia absentibus ut presentibus (añadido al margen, de otra mano: et tutori ac balio vestris) necnon et prothonotario ac notario subscripto tanquam publice persone habere a nobis pro vobis et omnibus illis quorum interest et intererit ac interesse potest et poterit legitime stipulanti et recipiente, ac eciam juramus per Dominum Deum et eius sancta quatuor evangelia, manibus nostris corporaliter tacta, in posse dicti prothonotari nostri ac notari subscripti predicta omnia et singula, prout superius a nobis sunt dicta, rata, grata et firma habere et per nos et successores nostros tenere et conservare eaque attendere et complere et contra non facere vel venire ratione ingratitudinis aut aliquis iuris causa vel eciam ratione sub bonorum nostrorum omnium ypoteca. Mandantes cum presenti, quam vice epistole gerere volumus, quod in hoc casu heredi aut successoribus nostris quibuscumque magistro justiciario dicti regni Sicilie, justiciariis, admirato, senescallo maiori Panormi, capitaneis et juratis ac aliis universis et singulis officialibus nostris et eorum locumtenentibus cuiuscumque condicionis existant in dicto regno et insulis eidem adiacentibus constitutis et constituendis, quod donacionem et concessionem nostras huiusmodi teneant inviolabiliter et observent et non contraveniant nec aliquem contravenire permittant aliqua ratione, iure seu causa, non obstante lege sive iure dicente donaciones propter ingratitudine vel alia quamvis causam (nota al margen, de otra mano: vide si sunt necesarie alie rerum) posse revocari vel irritari cum lege, et omnibus aliis legibus, usibus, consuetudinibus et aliis quibuscumque hiis obviantibus expresse et de certa ciencia renunciamus. Et supplentes ex nostre regie plenitudine potestatis omnem deffectum. Siquis forsitan intervenerint in predictis, volumus quod de hiis fiant et tradant vobis et vestris ac aliis quorum intersit tot quot volueritis et voluerint publica instrumenta. Actum est hoc in monasterio Vallis Domicelle territori Barchinone in quadam camera vocata de la abadessa, tricesima prima die madii anno a nativitate Domini $\mathrm{M}^{\circ} \mathrm{CCCC}^{\circ}$ decimo.

Signum [espacio en blanco para el signo] Martini etc, qui (tachado: hec) predicta laudamus (tachado: concedimus; interlineado: firmamus) et juramus.

Testes sunt qui (interlineado: ad predicta) presentes fuerunt. 
Nunca antes se había editado este texto, que juzgamos auténtico por sus elementos formales, y veraz, por su inclusión en el protocolo del protonotario y notario que asistió en sus últimas horas al rey Martín I. Era de una importancia extraordinaria, por lo que no es de extrañar que hubiera intereses para mantenerlo oculto, pero no fue desconocido por los contemporáneos, pues el procurador de Federico, Ramon de Torrelles, comunicó su existencia, aunque de modo indirecto, al Parlamento de Cataluña durante la sesión de 4 de abril de $1411^{87}$. Lo reclamó Fernando de Antequera después de su designación, mediante una carta datada el 3 de septiembre de 1413 (el mismo día que juró ante las cortes aragonesas), dirigida a Ramon de Torrelles ${ }^{88}$. No ha podido pasar desapercibido a los historiadores, aunque sólo se haya conocido por referencias indirectas y no su tenor ${ }^{89}$, pues por afectar directamente a la sucesión en Sicilia y sentar un precedente en la de los territorios patrimoniales de la Corona (Aragón, Cataluña, Valencia, Mallorca y Cerdeña) hubo gran interés en hacer mucha sombra sobre su existencia, lo que fue fácil por las lúgubres y precipitadas circunstancias en las que se otorgó, sólo ante una reducida camarilla de servidores reales ${ }^{90}$.

En efecto, esta donación ínter vivos planteaba el problema central de la sucesión a la Corona de Aragón. Por lo general, se acepta que todo el proceso fue provocado por el deseo de Martín I de promover al trono a su nieto ilegítimo, para lo cual era fundamental la decisión del papa, a su vez muy preocupado por la cuestión del Cisma ${ }^{91}$. Federico nunca había sido abandonado por su real familia. Nacido hacia 1403, junto con su hermana pasó muy pronto a Barcelona, donde su abuelo, que le profesó un gran afecto, le educó, encargando su custodia a Antoni de Torrelles y su mujer, auxiliados por sus hijos Pere y Ramon ${ }^{92}$. En la primavera de 1409 se proyectó su enlace matrimonial, con Violante, hija de Jaime de Prades ${ }^{93}$. No cuajó pero es un indicio de que el rey Martín se preocupaba por el futuro de su nieto. El 14 de abril de 1409, había legitimado a Federico, para suceder a su padre en el condado de Luna y señorío de Segorbe y también para sucederle en el reino

87.- Cortes, t. VIII, pp. 48-49.

88.- ACA, Real Cancillería, reg. 2.401, f. 7r. Cfr. Enric BAgué, "Dos documents sobre l'infant Frederic, fill de Martí de Sicília i l'afer de la successió", Analecta sacra tarraconensia, XI (1935), p. 332.

89.- Es el caso de Zurita, que parece saber de él por la citada reclamación de Ramón de Torrelles ante el Parlamento de Cataluña (J. Zurita, Anales, lib. XI, 29).

90.- No da cuenta de todas estas complejidades Alfonso García GaLLo, "El derecho de sucesión del trono en la Corona de Aragón", Anuario de Historia del Derecho Español, XXXV (1966), pp. 56-57, que simplifica en extremo la cuestión en lo que se refiere a los derechos de Federico.

91.- Fue la opinión de Valla, compartida por J. Zurita, Anales, X, 89, y XI, 9, y muy extendida después, por ejemplo en F. Soldevila, Història, vol. II, pp. 552-555.

92.- A. Closas, El nét, pp. 4-17.

93.- Colección, t. I, doc. XIX, pp. 105-110. 
de Sicilia, excluyendo sus reinos patrimoniales (Aragón, Cataluña, Valencia, Mallorca y Cerdeña), en caso de que muriera sin hijos legítimos el infante Martín ${ }^{94}$. A su vez, este, en la primera cláusula de su testamento otorgado en Cagliari a 25 de julio de 1409, había instituido muy claramente a su padre como su heredero universal. Con la misma claridad, en la segunda cláusula dotó a Federico con el condado de Luna, sin más legados ni sustituciones. No olvidó tampoco dotar a su hija natural Violante y a las madres de ambos niños, Tarsia Rizzari y Agatuzza de'Pesci respectivamente, que encomendaba a su padre ${ }^{95}$. No obstante estas limitaciones testamentarias, después de la muerte de Martín el Joven cuajó en Sicilia un interés por tener como rey a Federico, alentado por Martín I ${ }^{96}$, sin que el afecto del viejo monarca por su nieto fuese suficiente para vencer los reparos legales y sin que este favoritismo excediera estrictamente de lo que atañía a la sucesión del reino de Sicilia (continuando la tradición de los reyes aragoneses respecto de la vinculación de esta isla con la Corona), excluyéndole de los reinos patrimoniales, como ya lo había dejado bien claro en su legitimación de 14 de abril de 1409 y como parece mantenerse en la legitimación otorgada por Benedicto XIII el 20 de agosto de $1410^{97}$, que debió ser la prevista para el $1^{\circ}$ de junio de ese año y que hubo de aplazarse por el inesperado fallecimiento de Martín $\mathrm{I}^{98}$.

La donación del reino de Sicilia a su nieto la complementó el rey, a causa de su menor edad, con el nombramiento de un tutor y administrador en su nombre de aquel reino, cargo que recayó en el gran privado del rey Pere de

94.- Este privilegio de legitimación, muy citado pero poco conocido, se encuentra en ACA, Real Cancillería, reg. 2.206, ff. 165v-166r. Cfr. A. de Bofarull, Historia, t. V, p. 121, n. 2; y J. ZuritA, Anales, lib. XI, 6.

95.- Publicado en Colección, t. I, doc. XXV, pp. 120-127. El original en ACA, Real Cancillería, Pergaminos de Martín I, núm. 454. Cfr. J. Zurita, Anales, X, 88. Sobre Tarzia y Agatuccia, Giuseppe BeCCARIA, Spigolature sulla vita privata di re Martino in Sicilia, Palermo, 1884, pp. 90-96.

96.- Colección, t. I, doc. XXVI, pp. 131-132. Cfr. Alberto Boscolo, La política italiana di Martino il Vecchio re d'Aragona, Pàdua, 1962, pp. 168-169. El rey lo puso de manifiesto en una larga y conocida carta a su privado, Pere de Torrelles, de 20 de febrero de 1410 (ACA, Real Cancillería, reg. 2.238, ff. 115r-117r). Cfr. E. BAgué, "Dos documents", pp. 323-332.

97.- J. Zurita, Anales, lib. XI, 6. Los fundamentos jurídicos de la candidatura de Federico fueron refutados con razonamientos de peso por el jurista castellano Vicente Arias de Balboa, contestando a las cuestiones que el rey Martín planteó a la comisión por él designada. Cfr. Vicente ARIAs dE BALBOA, El derecho de sucesión en el trono: la sucesión de Martín I el Humano (1410-1412), edición y estudio introductorio de Antonio Pérez Martín, Madrid, 1999. Los argumentos de Arias de Balboa, "con cuya autoridad y opinión se conformaron todos" en Castilla, sustentaron las alegaciones presentadas por el infante Fernando ante los compromisarios de Caspe (J. Zurita, Anales, XI, 83).

98.- No he podido consultar el texto de esta bula, que los historiadores citan pero no editan. J. ZURITA, Anales, XI, 83, se refiere de pasada a otra legitimación que Martín I consiguió del papa Inocencio VII (cuyo pontificado transcurrió en Roma entre el 17 de octubre de 1404 y el 6 de noviembre de 1406), sin que haya podido comprobarlo, pues parece haber cierta contradicción en las fechas. 
Torrelles ${ }^{99}$, instrumento que se extendió también en la mañana del 31 de mayo de 1410 y que que se perfeccionó con el juramento del cargo que en su nombre, por estar ausente como capitán general de Cerdeña, prestó su hermano Ramon de Torrelles ${ }^{100}$. Se trata del documento señalado con el núm. [12] (que acaba en el núm. [19]) del protocolo de Sescomes. Con él, Martín I revalidaba la tutoría de Federico que, con muy amplios poderes, ya había asignado a Pere de Torrelles el 22 de agosto de 1409, en un instrumento en el que específicamente el monarca se refería a su nieto como pupillo "per nos jam legitimato" 101 . Como se sabe, muerto su poderoso tutor Pere de Torrelles y abandonado por Benedicto XIII, la causa de Federico quedó desamparada.

\section{Legados a la Reina Margarita}

De este grupo de actos e instrumentos jurídicos con los cuales el rey Martín arregló su herencia y sucesión durante la noche del día 30 y la mañana

99.- Pere de Torrellas había sido camarero y consejero de Martín el Humano desde 1398, y camarero mayor y camarlengo en 1402 (M. T. FERRER, "El Consell reial”, p. 187). En 1399, fue el portaestandarte real durante la ceremonia de coronación de Martín I, encargado de llevar a espaldas del rey su yelmo y su escudo (J. Zurita, Anales, X, 69). En 1408 fue nombrado capitán general de la armada enviada a Cerdeña (su nombramiento en ACA, Real Cancillería, reg. 2.314, f. 20r-v de la tercera numeración). Por su poder, de él se decía en aquel tiempo que era un "pequeño rey". Fue mariscal del ejército aragonés en la batalla de Sanluri. Según Zurita, entre los del consejo real de Martín I, "el que fue preferido a todos en el favor del rey y el que tuvo todo el poder y gobierno de lo que pendía de su voluntad y albedrío fue siempre Pedro de Torrellas su gran privado" (J. Zurita, Anales, X, 91). Como virrey, en Cerdeña mostró grandes aptitudes para la defensa de la posición aragonesa en la isla, a pesar de la difícil situación en la que se encontró tras fallecer el rey (ibídem, XI, 5 y 16). Allí murió de peste a principios de 1411, pues la noticia llegó al parlamento catalán el 14 de febrero de ese año (ibídem, XI, 27 y 28).

100.- Ramon de Torrellas fue también consejero y camarero del rey en 1398, camarero mayor en 1405 y camarlengo en 1408 (M. T. Ferrer, "El Consell reial”, p. 187). Pertenecía al consejo del rey en 1410 (J. Zurita, Anales, X, 91). Tras la muerte de Martín I, fue apresado en Barcelona. Los consejeros de la ciudad intercedieron por él. Liberado, marchó a Segorbe para hacerse cargo de la persona de Federico, junto con el obispo de aquella diócesis y Vidal de Blanes (ibídem, XI, 5 y 14). En 1411, abogó ante el Parlamento de Cataluña por la causa del nieto de Martín I, recordando que el rey lo había legitimado para la sucesión de Sicilia y que le había donado este reino, lo cual le había sido solicitado por la embajada siciliana. Ante la degradación de la situación de la isla encareció al Parlamento a tomar resoluciones (ibídem, XI, 29). En enero de 1412 pasa a Sicilia, con la embajada del Parlamento de Cataluña (ibídem, XI, 76). Se mantuvo en la defensa de la causa de Federico hasta la sentencia de Caspe (ibídem, XI, 81). En 1413, está al servicio del rey Ladislao I y actúa como su embajador ante Fernando I (ibídem, XII, 23). Muerto este, en 1417 pasa a servir a Alfonso V como patrón de galeras en Cerdeña (ibídem, XII, 65), aunque toma el partido de los barones enfrentados al monarca por la ordenación de su casa en 1418 (ibídem, XII, 68). Todavía interviene en las Cortes de Valderrobles de 1429: en ese momento actúa como procurador del rey de Navarra en tanto que conde de Ribagorza (ibídem XIII, 55).

101.- Colección, t. I, doc. XXXIII, pp. 148-152. 
del 31 de mayo, destaca también el que inicia el protocolo de Sescomes: la donación mortis causa a la reina Margarita, esposa del monarca. De este documento, teníamos noticias indirectas y fue el que explica que el cuaderno de Sescomes saliera de nuevo la luz en 1443 con motivo de las reclamaciones surgidas por su causa. En su versión completa, lo creemos también inédito, por lo que damos aquí su trascripción:

(Al encabezamiento:) Domine regine Margarite donacio causa mortis eidem facta per dominum regem quondam.

(Al margen, de otra mano): Est in libro et $\mathrm{p}$.

In Christi nomine. Pateat universis quod nos Martinus Dei gratia rex Aragonum, Sicilie, etc. Corporali detenti infirmitate de qua mortis periculum pertimemus, (tachado: animadvertentes quod nos) (interlineado, de otra mano: in nostro tamen pleno sensu cum firma loquela quia) ${ }^{102}$ die erina (interlineado, de otra mano: ex causa mortis nostre instantis) habentes (tachado: respectum) debitum respectum ad grata, multum placida et accepta servicia per vos serenissimam Margaritam, conjugem nostram carissimam, nobis prestita et que continue in huiusmodi nostra infirmitate impeduntur ${ }^{103}$ dedisse $^{104}$ et concessisse ${ }^{105}$ vobis (tachado: dicte) serenissime Margarita, coniugi nostre carissime, omnia bona nostra mobilia et eciam omnia jocalia nostra quae habemus aut nobis pertineant ubicumque sint et in posse quorumcumque personarum existant, et eciam palacium nostrum minus quod est in civitate Barchinone situatum, necnon eciam domum nostram de Bellesguard territori Barchinone. $\mathrm{Et}^{106}$ quod yocalia nostra quae impignorata existunt pro certis peccunie quantitatibus redimeantur de aliis bonis nostris ab hiis quibus impignorata fuerunt, ita quod vos ea omnia haberetis quita ${ }^{107}$, libera atque francha ${ }^{108}$. Et eciam voluisse ${ }^{109}$ et ordinasse ${ }^{110}$ quod per confirmacionem quam ipsa die erina fecimus de testamento per nos facto nullum fieret perjudicium ipsi donacioni ac concesioni vobis dicte regine per nos (corregido de otra mano: facte) ante confirmacionem (tachado: su) predictam, propterea volentes donacionem et concessionem predictas debitum sortiri effectum et in futurum publicis mostrari eciam documentis. Tenore presentis, gratia et nostra certa sciencia $^{111}$ pro uberiori et firmiori ac habundanti cautela premissorum dona-

102.- Al margen, de otra mano: "Bonum ut credo esset quod postquam fit mencio de egritudine et mortis periculo propter infirmitatem, fiet mencio de eius sanitate mentis".

103.- Desde "habentes" hasta "impenduntur", subrayado y anulado.

104.- Corregido de otra mano: "dedimus".

105.- Corregido de otra mano: "concessimus".

106.- Interlineado de otra mano: "voluimus".

107.- Corregido de otra mano sobre "quitia",

108.- Interlineado de otra mano: "ab omne pignoris".

109.- Corregido de otra mano: "voluimus".

110.- Corregido de otra mano: "ordinamus",

111.- Intercalado al margen, de otra mano: "in voluntate premissa consistentes et perseverantes, eamdem donacionem confirmamus et". 
cione scilicet que dicitur causa mortis donamus ${ }^{112}$ vobis, eidem serenissime Margarita coniugi nostre carissime presenti, (tachado: dictum) palacium nostrum minus (interlineado: predictum) quod est in dicta civitate Barchinone situatum, cum omnibus suis menbris (sic), juribus et pertinenciis universis, et eciam dictam domum nostram de Bellesguard territori Barchinone cum omnibus suis possessionibus, tenedonibus et aliis (tachado: suis) juribus et pertinenciis universis, necnon omnia yocalia atque bona nostra mobilia supradicta que habemus aut nobis pertineant ubicumque sint et in posse quorumcumque personarum existant. Volentes eciam et ordinantes quod dicta (tachado: jo) yocalia nostra que impignorata existunt pro certis peccunie quantitatibus redimantur de aliis bonis nostris ab hiis quibus impignorata fuerunt, ita quod vos ea omnia habeatis quitia, libera atque francha ut prefertur. Hanc itaque donacionem causa mortis facimus vobis dicte regine ut prefertur de omnibus et singulis supradictis ${ }^{113}$ sicut melius dici potestet intellegi ad vestri salvamentum et bonum eciam intellectum. Et promittimus solemne stipulacione, intervenientibus vobis prefate regine et prothonotario ac notario infrascripto tanquam publice persone pro vobis et pro aliis eciam personis quorum interese et intererit legitime paciscenti et stipulanti, sub obligacione bonorum nostrorum, quod heredes seu sucesores aut ${ }^{114}$ manumisores nostri quicumque predicta omnia et singula per nos vobis supra (tachado: donata) causa mortis donata habebunt ${ }^{115}$, tenebunt et observabunt ${ }^{116}$ et in nullo contrafacient vel venient aliquo iure, causa vel eciam ratione. Actum est hoc in monasterio Vallis Domicelle territorio Barchinone tricesima prima madii anno a nativitate Domini $\mathrm{M}^{\circ} \mathrm{CCCC}^{\circ}$ decimo.

(Tachado: Testes sunt) Signum Martini etc, qui haec concedimus et firmamus.

Testes sunt qui presentis fuerunt (tachado: nobiles Rogerius Bernardus de Pallars), (intercalado y tachado: Geraldus Alamanii de Cervilione, gubernator [sigue la línea en el f. 8, pieza núm. 7] Cathalonie), (tachado: Petrus de Cervislione ( $\mathrm{sic}$ ) maiordomus), [sigue la línea en el $f$. 8, pieza núm. 7:] (tachado: Raymundo de Sancto Miniato, camerario, militibus), Francisco d'Aranda, donato Porte Celi et Ludovico Aguilo domicello.

Item nobilis Rogerius de Montecatheno dixit haec vel simila verba in effectu. Senyor, si als es de vos, que Deu nos faes tant de mal queus perdessem, los vostres bens mobles, plau vos que sien tots de la senyora regina. Et dictum dominus respondens dixit hoc. (Intercalado: Testes) etc. Et post paulum (tachado: Rogerius Bernardus de Pallars) dictus nobilis Rogerius dixit etc: Senyor, vos havets dit queus plau vos que tots los vostres bens mobles sien de la senyora regina, plau vos que los dits bens mobles e les

112.- Interlineado, de otra mano: "iterum".

113.- Intercalado al margen, de otra mano: "Bonum videtur si hic adirent ista verba: si nos ex hanc egritudine mori contingit et non revocaverimus seu revocavisemus eamdem donacionem aut vos dictam reginam premori nobis contingat vel contingerit".

114.- Corregido, de otra mano: "et".

115.- Intercalado al margen, de otra mano: "grata et rata".

116.- Interlineado, de otra mano: "pro nobis ac execucione voluntatis nostre". 
vostres yoyes sien de la senyora regina e lo palau menor e la torre de Bellesguard. Et dictus dominus rex respondens dixit hoc. Et deinde cum fuissent domino regi predicto per episcopum [et cetera] dicta haec verba vel similia in effectu: Senyor, algunes yoyes vostres son empenyorades, plau vos que sien quitades de vostres bens e que remanguen quities a la senyora regina. Quiquidem dominus respondens dixit hoc. Postea die sabbati XXXI ${ }^{\mathrm{a}}$ madii dictus episcopus reducens ad memoriam dicti domino regi predicta iam sibi die altera dicta et explicata dixit hec (sigue el texto en el f. 8, que equivale a la pieza núm. [7]) verba vel similia in effectu: Senyor (tachado: plauraus) plau vos que (tachado: vos) tots los bens mobles vostres e yoyes vostres e lo palau menor e la torre de Bellesguard sien de la senyora regina e quen sia feta carta de donacio a la dita senyora, respondens dixit hoc. Et continuo ego dictus prothonotarius repetens eidem domino verba predicta dixi: Senyor, plau vos donchs que tots los bens mobles e yoyes vostres e lo palau menor de Barchinona e la torre de Bellesguard sien de la senyora regina e que lin sien fetas cartes de donacio e altres a tot son profit a consell de vostre vicecanciller, respondens dixit hoc. De quibus etc.

[Alf. 8v:] Al molt honorable senyor en Francesc de Alçamora etc.

Las correcciones marcadas en nota corresponden a las realizadas por Esperandéu Cardona. Las marcadas en el texto son de otra mano, que parecen ser las del protonotario, y que recogen las observaciones de Cardona. El papel conserva los dobleces por donde fue plegado, y al dorso el sobrescrito: "Al molt honorable senyor en Francesc de Alçamora etc." Este fue un notario que ejerció en Barcelona desde fines del siglo XIV y que pertenecía al círculo de escribanos reales ${ }^{117}$. Debió de ser uno de los escribanos que trabajaron intensamente durante los días 30 y 31 de mayo en la preparación de los numerosos instrumentos que integran el protocolo de Sescomes: en este caso, se le remitió la minuta del acta con la declaración del rey Martín en relación con la herencia de la reina Margarita, que había de formalizarse en esta pieza núm. [1].

Como vemos, esta pieza tiene dos partes. La primera, por orden topográfico, es el instrumento de donación; le sigue el acta con la expresión de la voluntad del monarca respecto de este asunto, anterior en el tiempo a aquella: constituyen el juego de actio y conscriptio como fases sucesivas de la génesis

117.- En el Arxiu del Castell de Vilassar de Dalt se conservan varias escrituras expedidas por él de los años 1386 (11-2-19 (A-5), 1387 (1-28-40 (E-4) y 1-28-43 (E-4); y 1388 (32-1-02 (A-2). En 1393 poseía una casa en la judería de Barcelona (Xavier Pons I CASACUBERTA, "La cristianització dels calls de Barcelona arran dels avalots de 1391 i la seva integració a la resta de la ciutat”, en XII Congrés d'Història de Barcelona. Historiografia Barcelonina. Del mite a la comprensió. Arxiu Històric de la Ciutat de Barcelona, Barcelona, 2011, p. 13). El 27 de enero de 1391, la reina Violant requirió su presencia en el pleito que la enfrentaba a la reina viuda Sibila (María Teresa Ferrer i Mallol, "Un aragonés consejero de Juan I y de Martín el Humano: Francisco de Aranda", Homenaje a la profesora Carmen Orcástegui Gros, vol. 1, Zaragoza, 1999, p. 533, n. 15). 
documental tan estudiada por los diplomatistas. Salvo Roger Bernat de Pallars (de quien sabemos que estaba en otras listas de testigos de aquellos días), los otros cinco testigos (Guerau Alemany de Cervelló, Pere de Cervelló, Ramon de Sentmenat, Francisco de Aranda y Luis Aguiló) lo fueron también del acta de la última voluntad del rey Martín del día 30 de mayo, y todos ellos, menos Ramon de Sentmenat, figuraron también en la del día 31 de mayo. Las fórmulas del acta de donación a favor de la reina Margarita coinciden con las que ya conocemos sobre la sucesión de los reinos, sobre los oficios y sobre la confirmación del testamento. En la fase de la actio, durante la noche del 30, actuando un personaje de la corte como portavoz, se interroga al monarca sobre su voluntad, quien manifiesta su aquiescencia mediante una simple afirmación (hoc) a la misma pregunta hecha bajo diversas fórmulas por distintos individuos, para despejar cualquier duda o sospecha, incluidas las de enajenación mental del moribundo; el día 31 se reitera este procedimiento, añadiendo en boca del protonotario, como fedatario público, la fórmula que permita redactar los instrumentos jurídicos pertinentes (lo cual constituye lo que en términos diplomáticos se conoce como iussio-rogatio); se suscribe el acta por un número suficiente de testigos, que desde luego no son necesariamente todos los presentes al acto y, finalmente, ya en la fase de conscriptio, se redacta el documento en cuestión, que por las especiales circunstancias del caso ha de hacerse a toda prisa para llegar a expedirlo antes de la muerte del otorgante, de modo que se solapan cada uno de los sucesivos estados diplomáticos de la génesis documental (imbrevatio, mundum, recognitio, registratio, validatio). El protonotario, el vicecanciller y los escribanos debieron estar trabajando toda la noche del 30 al 31 de mayo para llegar a tiempo y tener listos los documentos antes de que el monarca falleciera, pues el tiempo corría en su contra (hasta el punto de que, en el resumen que encabeza el documento, el rey figura ya como difunto). Al acta del día 30 en favor de la reina Margarita se hace referencia al principio del tenor de la donación del día 31. También en este documento se menciona la confirmación del testamento hecha, como vimos, el día 30.

Félix Duran i Cañameras mencionó este documento, del que dijo no conocerse ni el original ni la copia auténtica, sino solo una copia registrada en el f. 66 del registro "Diversorum secundus" del Archivo Municipal de Barcelona ${ }^{118}$. La donación mortis causa a favor de la reina Margarita fue ejecutada, al contrario de lo ocurrido con la del reino de Sicilia a Federico.

118.- F. Durán, Margarida de Prades, p. 16. Sin embargo, de este documento se conserva una copia notarial de 4 de septiembre de 1417, procedente del archivo del Hospital de la Santa Creu de Barcelona, hoy en la Biblioteca de Cataluña, perg. 590. 
En septiembre de 1410, la reina Margarita procedió a inventariar los bienes muebles que se encontraban en el palacio real mayor, la librería, la capilla real y el guardarropa ${ }^{119}$. El 12 de noviembre de 1410, la reina viuda, a través precisamente de Roger Bernat de Pallars, presentó ante el Parlamento de Cataluña una solicitud para entrar en posesión de los bienes que fueron del rey Martín y ser alimentada de ellos en el año de duelo, y después cobrar sus frutos hasta que fuese pagada su dote y lo que le pertenecía. Los parlamentarios no quisieron entrar a disputarle este derecho y aceptaron esta reclamación hasta que se declarase sucesor de la Corona ${ }^{120}$. La reina estuvo en posesión de la torre de Bellesguart y del palacio real menor de Barcelona, además de las joyas y otros bienes que le dejó su marido, con grandes dificultades pues sus apuros económicos fueron siempre considerables ${ }^{121}$. La donación mortis causa a la reina Margarita se menciona en un documento de 1419, exhumado por Duran i Cañameras, mediante el cual el rey Alfonso el Magnánimo le autorizó a vender, establecer en enfitéusis o empeñar los palacios que había heredado de su primer marido ${ }^{122}$.

\section{OTRAS DONACIONES}

Por último, en el protocolo o cuaderno de notas de Sescomes, junto a estas declaraciones de la voluntad del rey Martín I y los instrumentos notariales que la formalizaban, hay un grupo de documentos que contienen donaciones mortis causa o ínter vivos, realizadas por el monarca el último día de su vida, a favor de varios de sus servidores mas cercanos. Todos están expedidos en nombre del rey Martín I, refieren que el monarca se encuentra enfermo en peligro de muerte pero con su plena conciencia y habla (según la apostilla

119.- ACA Real Cancillería, reg. 2.326 (publicado por Jaume Massó I Torrents, "Inventari dels béns mobles del rei Martí d'Aragó", Revue Hispanique, núm. 12 (1905), pp. 413-590).

120.- Cortes, t. VII, Madrid, 1903, pp. 177-179; el parlamento deliberó este asunto en la sesión de $1^{\circ}$ de diciembre de 1410 (ibídem, pp. 230-231) y dio su respuesta en la de 9 de diciembre (ibídem, pp. 258259). Cfr. J. Zurita, Anales, lib. XI, 13. Otra reclamación a favor de socorrer económicamente a la reina la presentó su madre, Juana de Prades, ante el parlamento catalán en la sesión de 15 de marzo de 1412 y se examinó en los días siguientes (Cortes, t. IX, Madrid, 1905, pp. 433, 441, 455, 458, 463-464; e ibídem, vol. X, Madrid, 1906, p. 14).

121.- F. Durán, Margarida de Prades, pp. 18 y ss. Sobre la reina y las vicisitudes de su herencia, que fue un asunto recurrente durante años, véanse además IDEM, "Margarida de Prades", Butlletí de la Societat Catalana d'Estudis Històrics, I (1952), pp. 47-51; Diego ZaforteZa Musoles, "Segundas nupcias y viudez de una Reina aragonesa (1409-1451)", en IV Congreso de Historia de la Corona de Aragón, vol. II, Barcelona, 1970, pp. 516-550; Eufemiano ForT I Cogul, Margarida de Prades, Barcelona, 1960; Idem, La llegenda sobre Margarida de Prades, Barcelona, 1970; Francesca VenDrell i Gallostra, Margarida de Prades en el regnat de Ferran d'Antequera, Barcelona, 1984.

122.- ACA, reg. 2591, f. 68v. Cfr. F. Durán, Margarida de Prades, p. 40. 
de Esperandéu Cardona hecha en la donación a la reina Margarita), y vienen datadas: "Actum est hoc in monasterio Vallis Domicelle territorii Barchinone in quadam camera vocata de la Abadessa tricesima prima die madii anno a nativitate Domini $\mathrm{M}^{\circ} \mathrm{CCCC}^{\circ}$ decimo regnique nostre quintodecimo". Son las piezas núms. [2, 3, 4, 8, 10,11, 13, 14, 22, 23, 24, 25 у 26].

Con estas donaciones el rey Martín recompensó, en sus últimas horas de vida, a sus más inmediatos servidores, algunos de los cuales le rodeaban en su lecho de muerte, como Pere y Ramon de Sentmenat y Pere de Cervelló, mayordomos; Luis Aguiló y Ramon de Torrelles, camareros; o el abad de Ripoll, Berenguer de Rajadell, su confesor. De otros, como Ramon de Blanes, mayordomo, o Berenguer Arnau de Cervelló, camarlengo, no tenemos constancia que estuvieran presentes en estas escenas, pero tales mandas de última hora así parecen atestiguarlo: no todos los individuos que asistieron dejaron constancia documentada ${ }^{123}$. Finalmente, hay dos casos en el que el monarca actúa movido por escrúpulos de conciencia, como son las restituciones de bienes a la condesa de Ampurias y a Guillem Ramón de Moncada, de la rama siciliana de los condes de Augusta.

Como ocurre con los instrumentos relativos a Federico o a la reina Margarita, todos estas concesiones in artículo mortis van con las apostillas jurídicas de Espereandéu Cardona y con las correcciones del protonotario Sescomes, que las recogen, además de introducir por su cuenta otras enmiendas de estilo y observaciones menores, a veces reveladoras. Por ejemplo, en el núm. [22], al referirse el instrumento a la donación a favor de Ramón de Torrelles, se añade un interlineado con la expresión: "tanquam bene merito et condigno", fórmula que se incluye en otras concesiones reales dadas ese mismo día en beneficio de otros servidores pero, en esta, una señal al pie remite a una nota, de letra de Sescomes, que en un tamaño ínfimo dice: "credo que hec verba non sint neccessaria" (f. 30r), muestra de esa mezquindad burocrática tan característica de las oficinas públicas que pervive a través de los siglos.

\section{CONCLUSIONES Y VALORACIONES}

¿Se mantuvo oculto este cuaderno y las disposiciones en él contenidas? Dado el número de asistentes, el secreto no era factible, porque se tra-

123.- Sabemos que andaban por allí otros grandes personajes, como Segur de Perapertusa, quien aparece en la lista de posibles testigos en el acta sobre los oficios trienales, pero de quien no tenemos otro testimonio que lo pruebe. Segur o Seguier de Perapertusa había sido portaestandarte aragonés en la batalla de Sanluri (J.-D. GARrido, Vida i regnat de Martí I, p. 263). En su testamento, el infante Martín le dejó un legado nada menos que de 10.000 florines (J. Zurita, Anales, X, 88). 
taba además de documentos públicos. Con independencia del protonotario (a quien hemos visto en determinado momento amenzar veladamente con revelar su contenido ante todos los parlamentos y complicar así aún más el proceso de declaración de sucesor), del vicecanciller, o del escribano, los testigos que suscribieron las actas o los documentos eran los únicos que podían estar al cabo de todo lo ocurrido en aquellas últimas horas. Su trayectoria política divergió. No es cierto que todos estuvieron ligados por unos mismos intereses o se declararan acérrimos antiurgelistas. Lo fue Guerau Alemany de Cervelló, gobernador de Cataluña, partidario inicial de Luis de Calabria, muy activo en todos los sucesos del Interregno y que se pasó después al bando trastamarista, al cual prestó grandes servicios ${ }^{124}$. Francisco de Aranda, hombre de trayectoria sinuosa, gozaba de la confianza de Benedicto XIII y fue un activo agente papal: sabedor del legado a favor de su nieto hecho por Martín I en su agonía, fue en principio partidario de Federico de Luna pero después varió su posición en el mismo sentido que el papa y san Vicente Ferrer y se adhirió al voto a favor de Fernando de Antequera $^{125}$. Por el contario, el catalán Guillem Ramon de Moncada fue un firme urgelista, llevado más bien por sus relaciones familiares, pero sin dejarse dominar por el sectarismo, porque en un principio llegó a apoyar a Luis de Calabria y después sirvió a Fernando de Antequera, aceptando la sentencia de Caspe y sin dejarse arrastrar a la revuelta del conde de Urgel. Pere de Cervelló, inmerso también en las discusiones políticas del Interregno, defendió en última instancia la candidatura de Federico, aunque murió en 1414 siendo camarlengo del infante Alfonso. El día 30 de mayo firmaron también el acta con la voluntad de Martín I, como testigos, Lluís de Prades, obispo de Mallorca (fiel a Benedicto XIII, a cuyas órdenes estuvo hasta la muerte); Ramon de Sentmenat, que falleció ese mismo año, y Roger de Moncada, gobernador de Mallorca, partidario de Jaume d'Urgell. Sus posiciones políticas, pues, tampoco fueron coincidentes, como no lo fueron la de otros individuos que aparecen en los documentos expedidos los días 30 y 31 de mayo. Es el caso de Roger Bernat de Pallars y Bernat de Fortià, que incluso militaron en partidos opuestos, sin que pueda decirse de ellos que en mayo de 1410 fueran declaradamente antiurgelistas, partidarios de la reina Violante, agentes del infante Fernando o defensores de Federico.

Si no ocultación, sí hubo, por causas diversas —incluido el interés crematístico de Sescomes - una cierta discreción respecto a lo dispuesto por el rey Martín en sus últimas horas, especialmente en lo relativo a las materias

124.- F. Soldevila, El Compromís de Casp, pp. 55-57, realiza una breve semblanza suya.

125.- Sobre este poderoso personaje, M. T. FERRER, "Un aragonés", pp. 531-562. 
políticas. No se conoció el contenido exacto del instrumento con la donación del reino de Sicilia otorgada a favor de Federico, ni nadie la reclamó nunca durante el Interregno. Tampoco trascendió la declaración real sobre una regencia o sobre los oficios trienales, si bien se sabía de ella de algún modo, porque fue lo que permitió a los gobernadores seguir en sus puestos y convocar los parlamentos para designar sucesor, sin que se requiriera un traslado de esta declaración. En otros casos, sabemos que algunos de estos instrumentos que afectaban a particulares fueron expedidos en su pública forma, porque en la matriz registral del protocolo de Sescomes se hace constar, en la cláusula de autorización del notario que cierra el tenor de la escritura, las correcciones y enmiendas realizadas sobre el mundum de la copia entregada a los beneficiarios, por ejemplo en el núm. [14] ${ }^{126}$. De hecho, se conserva el documento de fecha 4 de octubre de 1441 mediante el cual Alfonso V confirmó a Ramon de Sentmenat la donación que el rey Martín hizo a su padre in artículo mortis de la jurisdicción del lugar y parroquia de Polinyà, el día 31 de mayo de 1410, en Valldonzella, que se corresponde con nuestra pieza núm. [21] ${ }^{127}$. Obsérvese que las correcciones indicadas en la cláusula de cierre del notario coinciden con las que se señalaron ya en el protocolo de Sescomes ${ }^{128}$. Como se dice en este documento de confirmación de 1441, Ramon de Sentmenat hijo, desconocedor del instrumento de donación de 1410 ("non informatus de tenore preinserte carte"), en 13 de abril de 1435 había obtenido de Alfonso V otra concesión de la jurisdicción sobre Santiga, lo que es un indicio de la ignoracia que se tuvo del protocolo de Sescomes.

En las ciencias naturales, la explicación más sencilla acostumbra a ser la más probable. La imagen de la muerte de Martín I a la luz del protocolo de Sescomes nos muestra una visión algo diferente de la que teníamos hasta ahora, más natural y menos conspirativa, pero en realidad humana y políticamente más compleja y rica. Durante su agonía a lo largo de la noche del día 30 y la mañana del 31 de mayo de 1410, el rey Martín no contestó "hoc" tres veces a la misma pregunta reiterada en otras tantas ocasiones, como se

126.- ACA, Generalidad, vol. G-962, $2^{\text {a }}$ num., f. 21r: "Sig [en blanco] num mei Raimundi de Cumbis prothonotarii dicti domini regis auctoritateque regia notarii publici per totam terram et dominacionem eiusdem, qui predictis interfui et hec scribi feci et clausi. Corrigitur tamen in lineis IIII $^{\mathrm{a}}$ nobilium, et in XIII ${ }^{\mathrm{a}}$ factarum plenius, et in $\mathrm{XVII}^{\mathrm{a}}$ ac, et in prima testium frater Berengarius de Raiadello, abbas monasterii, et in II $^{\mathrm{a}}$ testium camerarius, et alibi in eadem d'Aranda". Otra similar en el núm. [21], ibídem, f. 28r.

127.- ACA, Real Cancillería, reg. 2.775, ff. 90v-95r.

128.- ACA, Generalidad, vol. G-962, 2ª numeración, f. 28r: "Signum Raimundi de Cumbis prothonotarii dicti domini regis auctoritateque regia notarii publici per totam terram et dominacionem eiusdem, qui predictis interfui et hec scribi fecit et clausit. Corrigitur tamen in lineis IIII ${ }^{a}$ igitur presentis, et in $\mathrm{XXXI}^{\mathrm{a}}$ facere ante presentem donationem et iurium cessionem”. 
creía hasta ahora, sino una docena de veces a preguntas diferentes. No se trata de una cuestión anecdótica. Esto ya no puede interpretarse como el estertor de un agonizante privado de sus facultades ${ }^{129}$, porque además consta que en una ocasión se negó a lo que le pedían, a propósito del nombramiento de una regencia. La muerte del rey fue inesperada, pero no súbita. Incluso aceptando el peor de los escenarios posibles (su hipotético envenenamiento), el cuaderno de Sescomes nos deja ver que tuvo tiempo para ordenar sus asuntos por encima de intrigas palaciegas, existieran o no: realizó numerosas donaciones, se ratificó en su testamento de 1407, donó el reino de Sicilia a su nieto, pensó sus respuestas antes de darlas, se levantaron varias actas sobre asuntos de gran calado, se prepararó un borrador de testamento nuncupativo que no prosperó... El soberano fue plenamente consciente de las dificultades de la sucesión y de la invalidez jurídica en que podían incurrir sus actos de última hora, formalmente revisados como mínimo por el vicecanciller y el protonotario. Martín I pudo hacer una señal inequívoca de que su voluntad era dejar sus reinos a Federico (como procedió con Sicilia), pero no fue así, lo que pone en cuestión la interpretación de Valla. A los otros candidatos ni siquiera los mencionó, aunque tuvo ocasión de hacerlo. Por lo que parece a la vista del cuaderno de sus últimas voluntades, Martín I se mantuvo coherentemente hasta su última hora en la vía por la que había optado desde el otoño-invierno de 1409-1410: la de dilucidar la sucesión por justicia ${ }^{130}$. El significado político de esta decisión es ya una cuestión de debate historiográfico.

129.- Para F. Soldevila, El Compromís de Casp, pp. 42-46, el "hoc" con la respuesta del rey a la "capciosa" pregunta de Gualbes fue "un so gutural, fàcilment exposat a confusió", "un simple hoc, que hem d'imaginar com a més aviat obscur en llavis d'un moribund que no afegeix cap altra paraula en tota l'escena", y que fue interpretado por los enemigos del conde de Urgell a su conveniencia.

130.- Lo intuyó R. Menéndez Pidal, "El Compromiso de Caspe”, esp. pp. XXXVIII-XLIV: "El Rey Martín (...) al morir no pronunció un Hoc inconsciente o forzado". 